\title{
Temporally Dissociable Mechanisms of Self-Control: Early Attentional Filtering Versus Late Value Modulation
}

\author{
Alison Harris, ${ }^{1,3}$ Todd Hare, ${ }^{2}$ and Antonio Rangel ${ }^{3,4}$ \\ ${ }^{1}$ Department of Psychology, Claremont McKenna College, Claremont, California 91711, ${ }^{2}$ Laboratory for Social and Neural Systems Research, Department of \\ Economics, University of Zurich, CH-8006 Zurich, Switzerland, and Departments of ${ }^{3}$ Humanities and Social Sciences, and ${ }^{4}$ Computational and Neural \\ Systems, California Institute of Technology, Pasadena, California 91125
}

Optimal decision-making often requires exercising self-control. A growing fMRI literature has implicated the dorsolateral prefrontal cortex (dlPFC) in successful self-control, but due to the limitations inherent in BOLD measures of brain activity, the neurocomputational role of this region has not been resolved. Here we exploit the high temporal resolution and whole-brain coverage of event-related potentials (ERPs) to test the hypothesis that dIPFC affects dietary self-control through two different mechanisms: attentional filtering and value modulation. Whereas attentional filtering of sensory input should occur early in the decision process, value modulation should occur later on, after the computation of stimulus values begins. Hungry human subjects were asked to make food choices while we measured neural activity using ERP in a natural condition, in which they responded freely and did not exhibit a tendency to regulate their diet, and in a self-control condition, in which they were given a financial incentive to lose weight. We then measured various neural markers associated with the attentional filtering and value modulation mechanisms across the decision period to test for changes in neural activity during the exercise of self-control. Consistent with the hypothesis, we found evidence for top-down attentional filtering early on in the decision period (150-200 ms poststimulus onset) as well as evidence for value modulation later in the process (450 - 650 $\mathrm{ms}$ poststimulus onset). We also found evidence that dlPFC plays a role in the deployment of both mechanisms.

\section{Introduction}

Optimal decision-making often requires foregoing attractive but ultimately inferior rewards in pursuit of more desirable goals. For example, to maintain a healthy weight one may choose an apple over a piece of chocolate cake. A growing human fMRI literature has implicated the dorsolateral prefrontal cortex (dlPFC) in successful self-control in domains ranging from diet to savings (Miller and Cohen, 2001; McClure et al., 2004, 2007; Ochsner and Gross, 2005; Camus et al., 2009; Mansouri et al., 2009; Figner et al., 2010; Kober et al., 2010; Mitchell, 2011; Philiastides et al., 2011; Hutcherson et al., 2012). Unfortunately, due to the limitations inherent in BOLD measures of brain activity, the precise neurocomputational role of dlPFC has not been resolved.

There are two natural models of what this role might be. The first one is based on previous findings from decision neuroscience. There is a growing consensus that ventromedial prefrontal cortex (vmPFC) encodes stimulus values that guide decisions at the time of choice (Kable and Glimcher, 2009; Rushworth et al., 2009; Rangel and Clithero, 2013). Given this, dlPFC could influence self-control by modulating the value signals computed in vmPFC so that they reflect more desirable attributes, such as the

\footnotetext{
Received Dec. 19, 2012; revised 0ct. 3, 2013; accepted 0ct. 24, 2013.

Author contributions: A.H., T.H., and A.R. designed research; A.H. performed research; A.H. analyzed data; A.H., T.H., and A.R. wrote the paper.

This work was supported by NSF Award No. 0851408.

Correspondence should be addressed to Dr Alison Harris, Claremont McKenna College, 850 Columbia Avenue, Claremont, CA 91711. E-mail: aharris@alum.mit.edu.

DOI:10.1523/JNEUROSCI.5816-12.2013

Copyright $\odot 2013$ the authors $\quad 0270-6474 / 13 / 3318917-15 \$ 15.00 / 0$
}

health of foods (Cho and Strafella, 2009; Hare et al., 2009, 2011; Baumgartner et al., 2011).

A second model comes from the perceptual, attention, and working memory literatures, which have found that the dlPFC is part of a large-scale attentional network that modulates early sensory responses (Kastner and Ungerleider, 2001; Yamasaki et al., 2002; Buschman and Miller, 2007; Zanto and Gazzaley, 2009; Zanto et al., 2010, 2011; Lennert and Martinez-Trujillo, 2011). This phenomenon, often called attentional filtering, could aid in self-control by reducing the neural processing devoted to distracting, goal-irrelevant items: for example, via suppression of perceptual responses when tempting foods are likely to be present.

A critical difference between these two accounts lies in their timing. If self-control reflects dynamic attentional filtering of sensory input, there should be differential activity associated with self-control success versus failure early in perceptual processing. In contrast, value modulation should occur during vmPFC value computations, starting $\sim 400 \mathrm{~ms}$ poststimulus onset (Harris et al., 2011).

Here we exploited the high temporal resolution and wholebrain coverage of event-related potentials to test the hypothesis that both mechanisms are at work in simple dietary self-control. Subjects were asked to make food choices while we measured neural activity using event-related potentials (ERPs) in a natural condition, where they responded freely without tending to regulate their diet, and in a self-control condition, in which they were given a financial incentive to lose weight. We then measured various markers associated with attentional filtering and value 
A

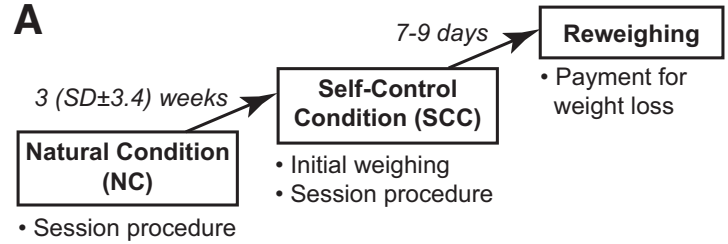

B

\begin{tabular}{|c|c|c|c|c|} 
I. Set-Up & \multicolumn{3}{|c|}{ II. EEG } & III. Clean-Up \\
\hline $\begin{array}{c}\text { Health \& } \\
\text { Taste Ratings }\end{array}$ & Decision & Decision & Decision & Outcome \\
$(45 \mathrm{~min})$ & $(20 \mathrm{~min})$ & $(20 \mathrm{~min})$ & $(20 \mathrm{~min})$ & $(30 \mathrm{~min})$
\end{tabular}

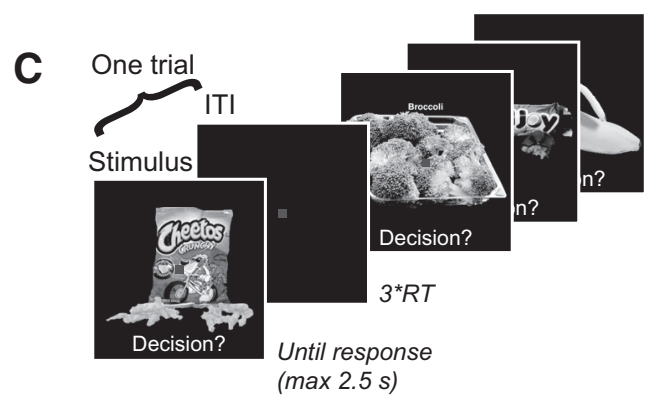

Figure 1. Experimental procedures. $\boldsymbol{A}$, Subjects made decisions about whether to eat snack foods varying in taste and health in two separate sessions: $\mathrm{NC}$, in which they were instructed to respond naturally, and $\mathrm{SCC}$, in which they were financially incentivized to lose weight to provide a motivation to exercise dietary self-control. Adherence to the weight loss incentive was measured in a separate final behavioral session. $\boldsymbol{B}$, Procedure for each EEG session. In Part I, subjects rated each food on taste and health. In Part II, subjects decided whether or not they would like to eat each food at the end of the experiment while their EEG responses were recorded. In Part III, the choice made by the subject in a randomly selected trial was implemented. C, Sample stimuli and screens from the decision-making task.

modulation across the decision process. We predicted that early sensory responses should reflect differential self-control success associated with attentional filtering, whereas changes in the value assigned to taste and health attributes should be visible later in the decision period. Furthermore, both mechanisms should be linked to dlPFC.

\section{Materials and Methods}

Subjects. Thirty-two right-handed subjects (ages 18-40, 21 males) from the local Caltech community participated in the study. Two additional subjects participated in the first experimental session, but were excluded from further participation because their choices revealed unusual food preferences, or their choices were so noisy that we could not reject the hypothesis that they were deciding randomly. Four subjects completed all experimental sessions, but their data were excluded from further analysis because their reported hunger levels were inconsistent with the experimental instructions described below (three subjects), or their EEG data exhibited persistent artifact after the preprocessing step (one subject). Subjects provided written informed consent before participation. All procedures were approved by Caltech's Institutional Review Board.

Stimuli. Subjects were presented with color pictures of 200 appetitive snack foods on a black background (Fig. 1; $576 \times 432$ pixels, $6.7^{\circ} \times 5^{\circ}$ visual angle). The set of food items was selected based on prior behavioral data to satisfy the following properties in a typical subject: (1) span the full range of the tastiness and healthiness scales (described below), and (2) exhibit a low degree of correlation between the tastiness and healthiness attributes across items. The set of foods ranged from fruits and vegetables to chips and candy bars.

Procedure. The task consisted of two electroencephalography (EEG) experimental sessions, followed by a short behavioral session (Fig. 1A). For reasons that will become obvious below, we refer to the first EEG session as the natural condition (NC), and to the second EEG session as the self-control condition (SCC).

Subjects were asked to fast for at least $2 \mathrm{~h}$ before the experiment. We monitored compliance through self-reported hunger ratings on a fivepoint scale ( $1=$ "not at all hungry" to $5=$ "very hungry") at the beginning of each session. A rating of 1 or 2 in either session was preselected as a criterion for exclusion from data analysis. Figure $1 B$ describes the timing of events within each of the two EEG sessions. First, subjects provided tastiness and healthiness ratings for each of the 200 foods using a fourpoint scale $(1=$ Strong-No, $2=$ Weak-No, $3=$ Weak-Yes, $4=$ StrongYes). On each trial, a food picture was displayed onscreen until the subject responded. Subjects entered their rating through a button press, with left-to-right order counterbalanced across subjects and sessions. The two types of ratings were blocked, with order counterbalanced across subjects. These ratings measure subjects' perceptions about how the taste and health attributes apply to each food, on each experimental session, and independently of the choices that they make later in the task.

Second, subjects performed a simple decision-making task, during which EEG recordings were made. As shown in Figure $1 C$, on every trial they were shown one food and had to decide whether or not they wanted to eat it at the end of the experiment. Subjects again entered their responses using a four-point scale $(1=$ Strong-No, $2=$ Weak-No, $3=$ Weak-Yes, $4=$ Strong-Yes). This allowed us to simultaneously measure their choice (yes/no) and the strength of their preference (strong/weak). Subjects cared about these choices because they knew that at the end of each of the two EEG sessions they would be required to stay in the laboratory for $30 \mathrm{~min}$, and that during that time, the only thing that they would be allowed to eat would be what they chose in a randomly selected trial. There were three runs of 200 trials each, with the foods presented in random order once per run, for a total of 600 trials. Each image was shown until subject response (maximum $2.5 \mathrm{~s}$ ). Subjects were instructed to respond as quickly and accurately as possible, and completed a short practice block before the actual experiment. Median reaction time (RT) was calculated cumulatively during each run, and the duration of the intertrial interval (ITI) was iteratively adjusted to $3 \times$ median(RT) to ensure that all decision-making computations were completed before the start of the next trial. Runs were subdivided into short blocks with intervening self-paced breaks. During the decision task, subjects were asked to maintain central fixation and minimize eye movements and blinks. Their performance was monitored with the recording equipment. The three runs were separated by 10 min breaks.

Third, a food was randomly chosen and the subject's choice for that food was implemented. In particular, the subject had to eat at least three bites of the selected item if he responded Strong- or Weak-Yes on two or more of the three presentations of the item, but was not given anything to eat if he responded Strong- or Weak-No on the majority of the trials for that item. Subjects were required to stay in the lab for $30 \mathrm{~min}$ regardless of the outcome.

The key difference between the two sessions was that subjects responded "naturally" during the NC session, but were financially incentivized to lose weight during the SCC session. In particular, at the beginning of the SCC session subjects were weighed using a Health-ometer Professional 349KLX digital medical scale (Pelstar LLC) while wearing a medical gown, and were told that they would be reweighed 7-9 d later when they returned to the lab for a final behavioral session. Reweighing was scheduled for the same time of day as the SCC session to account for daily fluctuations in weight. Subjects received a $\$ 100$ bonus for losing $0.25 \%$ of the initial weight, up to 1 pound, but only $\$ 50$ for losing $>1$ pound, and no bonus for weight gain. These incentives were chosen to induce subjects to exercise self-control during the SCC session choice task, while targeting a small weight loss during the rest of the week to discourage unhealthy dietary behaviors. We emphasize that the intervention itself was not of experimental interest, and was added simply to provide a strong incentive for exercising self-control during the SCC choices.

The NC and SCC sessions were separated by several weeks. We chose not to counterbalance the order of the two sessions across subjects, because it was unclear whether exposure to the self-control incentive would have long-lasting effects on behavior. However, although order and prac- 
tice effects might have influenced the level of expertise with the task, and thus reaction times and consistency in choices, they are unlikely to have contaminated the analysis strategy described below. In particular, as described below, most analyses involve comparisons only within trials of the SCC, or conjunctions between NC and SCC trials, which are not confounded by the presence of putative practice effects.

EEG data acquisition and preprocessing. EEG data were collected using a 128-channel HydroCel Geodesic Sensor Net (Electrical Geodesics) with $\mathrm{AgCl}$-plated electrodes. Evoked brain potentials were digitized continuously at $500 \mathrm{~Hz}$, and referenced to vertex electrode $\mathrm{Cz}$. Online filters consisted of a $200 \mathrm{~Hz}$ low-pass Bessel filter and a $0.1 \mathrm{~Hz}$ high-pass hardware filter. Impedances were kept $<50 \mathrm{k} \Omega$, with adjustments during the 10 min breaks between runs. Following each session, sensor positions were digitized using the Geodesic Photogrammetry System.

Data preprocessing was performed offline using the EEGLAB toolbox for Matlab (MathWorks; Delorme and Makeig, 2004). Data were rereferenced to an average reference and high-pass-filtered at $1 \mathrm{~Hz}$ using a two-way least-squares FIR filter to remove slow voltage drifts. Epochs of $2300 \mathrm{~ms}$ time-locked to stimulus onset (100 ms pre-, $2200 \mathrm{~ms}$ post-) were extracted.

Traditional artifact removal techniques based on rejecting trials are suboptimal for our datasets due to the unequal number of trials per condition. Given this, we identified and removed experimental artifacts using independent components analysis, implemented via second-order blind identification (SOBI; Belouchrani et al., 1997; Tang et al., 2005). Like other blind source separation algorithms, SOBI enables the effective identification of artifactual components, which can be removed while leaving the overall number of trials in each condition intact (Tang et al., 2005). Specifically, SOBI linearly "unmixes" the EEG data into a sum of temporally correlated and spatially fixed components, which can be classified as artifactual or nonartifactual based on their power spectra, scalp topographies, and activity. Task-related nonartifactual components are characterized by clear stimulus- or response-locking and meaningful scalp topography, whereas artifactual components reflect blinks, eye movement, muscle activity, sensor noise, and slow voltage drifts (Harris et al., 2011, their Fig. 3 shows a visualization of this artifact removal procedure). By projecting only nonartifactual components back onto the scalp, it is possible to obtain artifact-corrected brain signals (Jung et al., 2000). Following artifact removal, a stimulus-locked dataset was constructed with epochs of $1100 \mathrm{~ms}$ (100 ms pre- to $1000 \mathrm{~ms}$ poststimulus onset), baseline-corrected to the prestimulus period.

EEG: self-control success versus failure analysis. The goal of this analysis was to identify sensors and time windows that, during the SCC, exhibited differential activity for trials involving self-control successes and failures. To do this we divided the trials of the SCC session into three types: (1) successful self-control trials, in which subjects responded Yes to healthy but disliked foods, or No to liked but unhealthy foods; (2) failed selfcontrol trials, in which subjects responded No to healthy-disliked foods or Yes to liked-unhealthy foods; and (3) no-control trials that did not require self-control, involving healthy-liked or unhealthy-disliked items. For the purpose of this analysis, yes and no responses were aggregated across strong and weak levels. We then computed an averaged ERP response for each subject and sensor over nonoverlapping $50 \mathrm{~ms}$ windows, from 100 to $1000 \mathrm{~ms}$, separately for successful and failed self-control trials. This led to 128 sensor $\times 18$ time window maps for both types of trials, which were then compared using a two-tailed paired $t$ test.

Given the large number of statistical tests produced by the analyses described above and below, it was necessary to correct for multiple comparisons. Multiple-comparison corrections were implemented using permutation tests (Lage-Castellanos et al., 2010). To compare selfcontrol success and failure, an approximate permutation test was computed by reshuffling the condition labels 1000 times to obtain an empirical distribution of $t$ values, to which the actual $t$ values were then compared. The number of statistical comparisons was further limited by carrying out this analysis starting at $100 \mathrm{~ms}$ poststimulus onset, the earliest latency at which visual evoked potentials are reliably reported. The same comment applies to the regression analyses described below.

EEG: phase-locking analysis. The goal of this analysis was to test whether there was increased phase locking in the alpha range $(8-12 \mathrm{~Hz})$ between anterior and posterior sensors during successful self-control trials in the SCC. Current source density (CSD) estimates of the original vertex-referenced ERP data were computed using the CSD Toolbox for Matlab (MathWorks; Kayser and Tenke, 2006). The CSD transform produces reference-free data, minimizing spurious changes in phase coherence due to the use of an average reference. Additionally, due to its lower sensitivity to deep cortical sources, this measure is less influenced by artifactual volume-conducted signals.

Predefined sets of sensors covering frontal and occipital scalp regions were used as anterior and posterior sensors of interest (SOIs; see Fig. 5A, left). Time-frequency analyses were performed using the FieldTrip software package (Oostenveld et al., 2011). ERP data were averaged across each SOI and filtered in the alpha band $(8-12 \mathrm{~Hz})$ via convolution with complex Morlet wavelets (family ratio: $f_{0} / \sigma_{\mathrm{f}}=7$ ) and filter order of 400 ms. Phase-locking values (PLVs) were computed by measuring the intertrial variability of the phase difference at each time (Lachaux et al., 1999). The resulting PLVs are bounded between 0 and 1, with highly consistent phase differences yielding a PLV close to 1 , and random phase differences yielding a PLV close to 0 . Because previous analyses have found that frontal-occipital phase-locking associated with attentional modulation precedes the earliest cortical evoked potentials (Zanto et al., 2010, 2011), our PLV analysis focused on the window from $100 \mathrm{~ms}$ pre- to $300 \mathrm{~ms}$ poststimulus onset.

EEG: regression analysis of stimulus values. The goal of this analysis was to identify sensors and time windows in which neural activity at the time of decision was correlated with the stimulus value of the foods, as measured by the subject's decision. Evoked data for each trial between 100 and $1000 \mathrm{~ms}$ poststimulus onset were summed across $50 \mathrm{~ms}$ nonoverlapping windows for each sensor. For each subject, the EEG responses for each of the 128 sensors $\times 18$ time windows were then entered into a linear regression model of the form:

$$
y_{\text {sensor, time }}=\beta_{0}+\beta_{1} \text { Decision }+\beta_{2} \text { Arousal }+\varepsilon,
$$

where $y_{\text {sensor,time }}$ consists of trial-by-trial data (in $\mu \mathrm{V}$ ) for a particular sensor and time window, and $\beta_{0}$ is the average activity in the sensor. The Decision covariate measures the decision value $(1=$ Strong-No to $4=$ Strong-Yes). The Arousal covariate measures the strength of preference regardless of valence ( 0 for Weak-No or Weak-Yes, 1 for Strong-No or Strong-Yes). We included the latter covariate to take out the components of the signal that are related to arousal (Litt et al., 2011), which increases the statistical power of the linear model to identify value related activity. The linear regressor analysis generated a map of estimated regression coefficients (i.e., beta map) for every sensor, time window, and subject. We aggregated these maps into mixed-effect group estimates by computing one-sample $t$ tests versus zero across subjects for each sensor and time window. This led to output significant maps that identify sensors and windows in which evoked responses increase with stimulus value. Results were corrected for multiple comparisons using exact permutation tests, performed by calculating the linear models for every possible permutation of the four condition labels $(4 !=24)$. Observed $t$ values were compared with this empirical distribution, with those greater than or equal to the highest $t$ values, and less than or equal to the lowest $t$ values, considered as surviving multiple comparisons correction with a threshold of $p=1 / 24=0.04$ (one-tailed). Thus, given the small number of permutations, in practice the observed data had to fall at the extreme end of the permutation distribution to survive multiple-comparisons correction. These analyses were performed separately for the SC and NCC trials.

EEG: regression analysis of health and taste ratings. The goal of this analysis was to identify sensors and time windows in which evoked neural responses were linearly responsive to either the taste or the health ratings. The analyses were performed separately for the SC and NCC trials. The analysis is almost identical to the previous one, except that now the linear regression model is given by:

$$
y_{\text {sensor, time }}=\beta_{0}+\beta_{1} \text { Health }+\beta_{2} \text { Taste }+\varepsilon,
$$

where the Health and Taste covariates correspond to the subject's health and taste ratings entered in each session. The resulting beta maps were then compared using various paired $t$ tests. Permutation tests were used 
to correct for multiple comparisons, randomly shuffling the assignment of each subject's beta value maps to the two conditions (taste and health), and then calculating the resulting distribution of the $t$ statistics $(1000$ permutations).

EEG: Bayesian source reconstruction. The goal of this analysis was to localize the regions associated with the significant activity identified in the previous EEG analyses at the sensor level. Distributed source reconstructions were performed using SPM8 (Wellcome Department of Imaging Neuroscience, Institute of Neurology, London, UK).

The neural generators for any given waveform can be modeled as a combination of hundreds of small dipolar patches distributed across the cortical sheet. In our analysis, we first computed source reconstructions across the entire trial, -100 to $1000 \mathrm{~ms}$ from stimulus onset, which produces models of activity in all potential sources spanning this entire period. Following this large-scale reconstruction, sources were modeled for specific time windows of interest (WOIs) defined from the mixedeffects ERP regression analysis. Thus, for any given time window (e.g., $150-200 \mathrm{~ms}$ ), we could identify putative neural sources arising from the pattern of electrical potentials recorded at the scalp.

To pinpoint generators associated with specific cognitive effects, we used a "difference of localizations" approach in some analyses, and a "localization of differences" approach in others (Henson et al., 2007). These two analyses differ in the types of inferences being drawn. Specifically, a "localization of differences" (LoD) assumes that there exists a set of neural sources that represent different levels of the psychological variable of interest; for example, brain regions whose activity is correlated with stimulus values. Yet, because this analysis is designed to find sources representing all conditions, it cannot address the question of whether different conditions (e.g., self-control success and failure) are associated with spatially distinct brain networks. In this case, the more apt comparison is a "difference of localizations" (DoL), in which neural generators for the conditions are modeled separately, and the respective source estimates are then compared statistically.

Given this, to examine how self-control success and failure differentially recruit various brain networks, we used a DoL approach. In each subject, separate source reconstructions were performed for the waveforms associated with self-control success and failure. These reconstructions were then entered into a paired $t$ test analysis across subjects, producing statistical maps identifying sources differentially associated with self-control success or failure (Table 1).

In contrast, for our analyses of stimulus values, and of taste and health ratings, we relied on a LoD approach. The aim of source reconstruction here was to find regions showing a parametrically varying representation of these stimulus attributes, in line with subjects' decisions and ratings. To do so, we performed source reconstructions of the linear ordering from Strong-No to Strong-Yes. Difference waveforms were computed in each subject by multiplying the average waveforms for each of the conditions (Strong-No to Strong-Yes) by the corresponding weights $(-3$, $-1,+1,+3)$, and then summing across all weighted averages. This set of weights is commonly used to test for linear trends, weighting the data to find monotonically increasing responses with increasing ratings. Following source reconstruction, source estimates across subjects were entered into an $F$ test, allowing us to identify neural sources associated with parametric responses (Tables 2, 3).

In all reconstructions, source localization was performed via an empirical Bayesian algorithm (Friston et al., 2008) that constrains the underlying sources to provide a common explanation for evoked responses in all subjects (Litvak and Friston, 2008). In contrast to traditional dipole fitting, this approach does not require a priori assumptions about the number of sources or their spatial locations. Subjects were entered into the same source space using a "canonical mesh" based on SPM's template head model derived from the MNI brain. Individual subjects' sensor and fiducial coordinates, acquired with the Geodesic Photogrammetry System, were coregistered with the MRI coordinate system and matched to the cortical mesh using an iterative alignment algorithm. The source space was modeled using a boundary element model.

All reconstructions were then entered into statistical analyses $(t$ and F tests) to identify statistically significant source estimates across individuals. Results were visualized in terms of maximal intensity projection
Table 1. Peak MNI coordinates; self-control success versus failure SCC, $150-200 \mathrm{~ms}$

\begin{tabular}{|c|c|c|c|c|c|c|}
\hline \multirow{2}{*}{\multicolumn{2}{|c|}{$\frac{\text { No. Voxels }}{\begin{array}{l}\text { Self-control success }> \\
\text { self-control failure }\end{array}}$}} & \multicolumn{3}{|c|}{ Side Peak MNI coordinates } & \multirow[t]{2}{*}{$t$} & \multirow[t]{2}{*}{ MNI coordinate region } \\
\hline & & & & & & \\
\hline \multirow[t]{3}{*}{402} & $\mathrm{~L}$ & -32 & -20 & 20 & 11.6 & Insula \\
\hline & & -30 & -26 & 14 & 11.6 & \\
\hline & & -40 & -26 & 8 & 11.3 & \\
\hline 377 & $\mathrm{R}$ & 34 & -16 & 18 & 11.1 & Insula* \\
\hline 106 & $\mathrm{R}$ & 42 & 20 & -16 & 9.72 & Inferior frontal gyrus* \\
\hline 42 & $\mathrm{~L}$ & -40 & 20 & -16 & 8.10 & Inferior frontal gyrus \\
\hline \multirow[t]{3}{*}{184} & $\mathrm{R}$ & 40 & 50 & 16 & & $\begin{array}{l}\text { Dorsolateral prefrontal } \\
\text { cortex }\end{array}$ \\
\hline & & 38 & 40 & 34 & 7.93 & Middle frontal gyrus \\
\hline & & 38 & 46 & 24 & 7.72 & \\
\hline \multirow[t]{3}{*}{187} & $\mathrm{~L}$ & -36 & 42 & 28 & 7.95 & Dorsolateral prefrontal cortex \\
\hline & & -42 & 46 & 16 & 7.93 & Middle frontal gyrus \\
\hline & & -34 & 54 & 14 & 6.93 & \\
\hline
\end{tabular}

Self-control failure $>$

self-control success

\begin{tabular}{|c|c|c|c|c|c|}
\hline 86 & $\mathrm{~L}$ & -40 & -42 & 50 & -6.55 Inferior parietal lobe \\
\hline & & -26 & -40 & 48 & -6.67 \\
\hline & & -30 & -38 & 36 & -6.84 \\
\hline 144 & $\mathrm{R}$ & 42 & -40 & 42 & -6.55 Inferior parietal lobe \\
\hline & & 36 & -40 & 54 & -6.64 Intraparietal sulcus \\
\hline & & 28 & -34 & 38 & -6.70 \\
\hline 108 & $\mathrm{~L}$ & -60 & -38 & -14 & -6.55 Middle temporal gyrus \\
\hline & & -64 & -30 & -10 & -6.59 Inferior temporal gyrus \\
\hline & & -60 & -32 & -22 & -6.65 \\
\hline 171 & $\mathrm{R}$ & 44 & -32 & -2 & -6.51 Middle temporal gyrus \\
\hline & & 58 & -34 & -20 & -6.54 \\
\hline & & 58 & -40 & -10 & -6.55 \\
\hline 105 & $\mathrm{R}$ & 32 & -30 & -8 & -6.49 Hippocampus \\
\hline & & 24 & -18 & -22 & -6.50 Parahippocampal gyrus \\
\hline & & 18 & 0 & -12 & -6.51 \\
\hline 60 & $\mathrm{R}$ & 54 & -34 & 8 & -6.49 Superior temporal gyrus \\
\hline & & 54 & -42 & 10 & -6.54 Temporoparietal junction \\
\hline & & 64 & -28 & 0 & -6.85 \\
\hline
\end{tabular}

Clusters surviving FWE-corrected threshold $p<0.01$ ( $t \geq 6.49$ ) and cluster size threshold $k=5$. For this and all other tables, bold type indicates a cluster-level maximum, with separate $(>8 \mathrm{~mm})$ maxima listed in plain type. Because of the relatively low spatial resolution of EEG reconstruction, the source regions listed here do not precisely correspond to the coordinates, but rather reflect the general location of source activity within the specified cluster. *Clusters used as ROls in causal connectivity analysis.

(MIP) of the corresponding statistic. All statistics were corrected for multiple comparisons using a stringent familywise-error (FWE) corrected threshold of $p<0.01$. As displayed in Tables $1-3$, our analysis focused on cortical generators, because subcortical structures generally lack the coherent neural organization of pyramidal cortical cells and are unlikely to make a major contribution to potentials recorded at the scalp (Cohen et al., 2011).

EEG: Granger connectivity analysis. The goal of this analysis was to test for modulatory influence from dlPFC to vmPFC during the time windows associated with the computation of stimulus values, as identified by the previous analyses. Granger causality analysis was performed using the Granger Causal Connectivity Analysis toolbox (GCCA) for Matlab (MathWorks; Seth, 2010).

Given our interest in how regions associated with successful selfcontrol modulate stimulus value signals, we chose the regions of interest (ROIs) for the GCCA based on the results from previous analyses. In particular, the ROIs were defined to be sources that exhibited greater responses in successful over failed self-control trials over the conjunction of time windows showing significant differential effects (150-200 ms, $400-450 \mathrm{~ms}$, and $500-550 \mathrm{~ms}$ poststimulus onset), and using a liberal threshold of $p<0.005$ (uncorrected) to be inclusive. This conjunction analysis identified three bilateral ROIs: dlPFC, insula, and ventrolateral prefrontal cortex (vlPFC). Additionally, a vmPFC ROI was defined from the conjunction of stimulus value sources surviving FWE-corrected $p<$ 0.01 , from 250 to $350 \mathrm{~ms}$ and $450-650 \mathrm{~ms}$. 
Table 2. Peak MNI coordinates; stimulus value NC, $\mathbf{4 0 0}-\mathbf{5 0 0} \mathrm{ms}$

\begin{tabular}{|c|c|c|c|c|c|c|}
\hline \multirow{3}{*}{$\frac{\text { No. Voxels }}{240}$} & \multirow{3}{*}{$\begin{array}{l}\text { Side } \\
\mathrm{L}\end{array}$} & \multicolumn{3}{|c|}{ Peak MNI coordinates } & \multirow{2}{*}{$\begin{array}{ll}F \\
109.8\end{array}$} & \multirow{2}{*}{$\begin{array}{l}\text { MNI coordinate region } \\
\text { Inferior frontal gyrus }\end{array}$} \\
\hline & & -22 & 28 & -22 & & \\
\hline & & -28 & 0 & -16 & 60.8 & Orbitofrontal cortex \\
\hline \multirow[t]{3}{*}{512} & $\mathrm{R}$ & 18 & 26 & -22 & 99.0 & Inferior frontal gyrus \\
\hline & & 34 & -2 & -26 & 69.7 & Orbitofrontal cortex \\
\hline & & 26 & 16 & -16 & 65.1 & \\
\hline \multirow[t]{3}{*}{210} & R & 26 & -34 & -10 & 90.0 & Parahippocampal cortex \\
\hline & & 6 & -44 & 12 & 67.9 & Retrosplenial cortex \\
\hline & & 8 & -36 & 6 & 67.9 & Posterior cingulate cortex \\
\hline \multirow[t]{3}{*}{172} & $\mathrm{R}$ & 38 & 10 & 26 & 81.8 & Inferior frontal gyrus \\
\hline & & 46 & 0 & 38 & 66.1 & Middle frontal gyrus \\
\hline & & 34 & 0 & 28 & 60.2 & \\
\hline \multirow[t]{3}{*}{21} & $\mathrm{R}$ & 40 & -20 & 20 & 79.0 & Insula \\
\hline & & 36 & -12 & 18 & 56.4 & \\
\hline & & 40 & -28 & 22 & 50.0 & \\
\hline \multirow[t]{3}{*}{177} & $\mathrm{R}$ & 52 & -34 & 12 & 78.8 & Superior temporal gyrus \\
\hline & & 48 & -24 & -2 & 67.3 & \\
\hline & & 60 & -30 & 8 & 64.0 & \\
\hline \multirow[t]{3}{*}{85} & $\mathrm{R}$ & 48 & -68 & 34 & 76.3 & Angular gyrus \\
\hline & & 40 & -64 & 34 & 65.7 & Inferior parietal lobe \\
\hline & & 38 & -52 & 20 & 60.6 & \\
\hline \multirow[t]{3}{*}{69} & $\mathrm{~L}$ & -2 & 14 & 12 & 75.8 & Cingulate cortex \\
\hline & & -20 & -50 & 4 & 61.8 & Parahippocampal gyrus \\
\hline & & -4 & -26 & 10 & 56.8 & \\
\hline \multirow[t]{3}{*}{51} & L & -4 & 22 & 14 & 73.6 & Anterior cingulate cortex \\
\hline & & -10 & 4 & 42 & 59.0 & \\
\hline & & -6 & 20 & 24 & 53.13 & \\
\hline \multirow[t]{3}{*}{184} & L & -30 & -84 & 32 & 71.1 & Superior occipital gyrus \\
\hline & & -26 & -64 & 30 & 67.5 & Parietal lobe \\
\hline & & -22 & -60 & 40 & 59.8 & \\
\hline \multirow[t]{3}{*}{351} & R & 34 & -50 & 34 & 70.3 & Superior parietal lobule \\
\hline & & 32 & -60 & 32 & 68.7 & Precuneus \\
\hline & & 32 & -78 & 26 & 62.7 & \\
\hline 146 & L & -50 & -8 & -44 & 69.6 & Inferior temporal gyrus \\
\hline & & -38 & -22 & -20 & 57.9 & Parahippocampal gyrus \\
\hline & & -38 & -8 & -40 & 51.2 & \\
\hline 73 & $\mathrm{~L}$ & -10 & -36 & 60 & 69.3 & Paracentral lobule \\
\hline & & -6 & -46 & 70 & 65.2 & Precuneus \\
\hline 51 & R & 6 & 26 & 22 & 68.9 & Anterior cingulate cortex \\
\hline & & 4 & 18 & 24 & 61.7 & Ventromedial prefrontal cortex \\
\hline & & 6 & 34 & 12 & 50.6 & \\
\hline 187 & L & -34 & -50 & 58 & 68.6 & Parietal lobe \\
\hline & & -24 & -36 & 54 & 57.4 & \\
\hline 52 & L & -22 & 48 & 20 & 64.2 & Superior frontal gyrus \\
\hline 77 & $\mathrm{~L}$ & -40 & 8 & 32 & 61.4 & Inferior frontal gyrus \\
\hline & & -44 & 36 & 14 & 53.2 & \\
\hline & & -44 & 18 & 28 & 45.6 & \\
\hline 42 & $\mathrm{~L}$ & -14 & -30 & 62 & 57.8 & Paracentral lobule \\
\hline 6 & $\mathrm{R}$ & 4 & -40 & 22 & 55.4 & Posterior cingulate cortex \\
\hline 13 & L & -32 & 48 & 28 & 55.0 & Middle frontal gyrus \\
\hline & & -36 & 48 & 20 & 52.0 & \\
\hline 29 & $\mathrm{~L}$ & -58 & -26 & -10 & 54.6 & Middle temporal gyrus \\
\hline & & -58 & -18 & -12 & 52.1 & \\
\hline & & -52 & -28 & -4 & 49.0 & \\
\hline 6 & L & -48 & -72 & -8 & 54.5 & Inferior temporal lobe \\
\hline 11 & $\mathrm{R}$ & 0 & 14 & 18 & 52.4 & Cingulate cortex \\
\hline & & 0 & 6 & 20 & 52.0 & \\
\hline 13 & $\mathrm{R}$ & 52 & -48 & -24 & 52.3 & Fusiform gyrus \\
\hline 6 & L & -44 & -64 & 40 & 51.0 & Inferior parietal lobule \\
\hline 5 & L & -38 & -90 & -2 & 48.0 & Middle occipital gyrus \\
\hline 5 & $\mathrm{~L}$ & -34 & -38 & 44 & 46.1 & Parietal lobe \\
\hline
\end{tabular}

Clusters surviving FWE-corrected threshold $p<0.01(F=45.2)$ and cluster size threshold $k=5$.

The GCCA proceeded in several steps, all of them applied to data for the SCC only. First, we performed a Bayesian source reconstruction of the linear contrast for health ratings (least to most healthy) over the time window to generate a dipole intensity map for each subject (see Fig. $8 \mathrm{~A}$,
Table 3. Peak MNI coordinates; stimulus value $S C C, 450-650 \mathrm{~ms}$

\begin{tabular}{|c|c|c|c|c|c|c|}
\hline \multirow{4}{*}{$\begin{array}{l}\text { No. Voxels } \\
136\end{array}$} & \multirow{2}{*}{$\begin{array}{l}\text { Side } \\
R\end{array}$} & \multicolumn{3}{|c|}{ Peak MNI coordinates } & \multirow{2}{*}{$\begin{array}{ll}F \\
90.8\end{array}$} & \multirow{2}{*}{$\begin{array}{l}\text { MNI coordinate region } \\
\text { Ventromedial prefrontal cortex }\end{array}$} \\
\hline & & 12 & 26 & -16 & & \\
\hline & & 14 & 40 & 0 & 82.8 & Anterior cingulate cortex \\
\hline & & 10 & 36 & 10 & 77.7 & Medial orbitofrontal cortex \\
\hline \multirow[t]{3}{*}{183} & $\mathrm{~L}$ & -26 & 16 & -10 & 89.2 & Inferior frontal gyrus \\
\hline & & -30 & 28 & -20 & 76.2 & Insula \\
\hline & & -32 & -2 & -16 & 54.1 & \\
\hline \multirow{3}{*}{108} & $\mathrm{R}$ & 62 & -24 & -10 & 84.1 & Middle temporal gyrus \\
\hline & & 66 & -28 & -18 & 76.9 & Inferior temporal gyrus \\
\hline & & 58 & -30 & -16 & 73.2 & \\
\hline \multirow[t]{3}{*}{183} & $\mathrm{R}$ & 26 & -28 & -14 & 79.3 & Parahippocampal gyrus \\
\hline & & 16 & 0 & -12 & 74.4 & Limbic lobe \\
\hline & & 34 & -32 & -14 & 72.7 & \\
\hline \multirow[t]{2}{*}{84} & $\mathrm{~L}$ & -62 & -22 & -8 & 71.6 & Middle temporal gyrus \\
\hline & & -60 & -28 & -20 & 58.6 & Inferior temporal gyrus \\
\hline \multirow[t]{2}{*}{89} & $\mathrm{R}$ & 20 & 30 & -20 & 67.1 & Inferior frontal gyrus \\
\hline & & 28 & 16 & -12 & 49.5 & Orbitofrontal gyrus \\
\hline 21 & $\mathrm{R}$ & 16 & -38 & 46 & 62.8 & Parietal lobe \\
\hline \multirow[t]{3}{*}{68} & $\mathrm{~L}$ & -40 & 4 & -6 & 60.0 & Insula \\
\hline & & -42 & -6 & -16 & 55.3 & Superior temporal gyrus \\
\hline & & -48 & -6 & -22 & 49.9 & \\
\hline \multirow[t]{2}{*}{12} & & 0 & -34 & 24 & 58.1 & Posterior cingulate \\
\hline & & 0 & -38 & 16 & 55.4 & \\
\hline 13 & L & -4 & -24 & 34 & 57.8 & Posterior cingulate \\
\hline 10 & & 0 & -32 & 10 & 57.3 & Posterior cingulate \\
\hline \multirow[t]{2}{*}{39} & $\mathrm{~L}$ & -40 & -88 & 0 & 55.7 & Middle occipital gyrus \\
\hline & & -38 & -80 & -4 & 46.5 & \\
\hline \multirow[t]{2}{*}{55} & $\mathrm{R}$ & 48 & 2 & -16 & 55.3 & Superior temporal gyrus \\
\hline & & 46 & -4 & -22 & 51.1 & Superior temporal pole \\
\hline 12 & $\mathrm{R}$ & 32 & 54 & 2 & 55.0 & Middle frontal gyrus \\
\hline \multirow[t]{3}{*}{13} & $\mathrm{R}$ & 4 & -2 & 30 & 54.2 & Anterior cingulate \\
\hline & & 4 & 6 & 28 & 50.3 & \\
\hline & & 6 & 18 & 26 & 49.2 & \\
\hline 5 & $\mathrm{~L}$ & -16 & -74 & 42 & 51.6 & Superior parietal cortex \\
\hline 5 & $\mathrm{~L}$ & -14 & -72 & 36 & 50.2 & Precuneus \\
\hline 7 & $\mathrm{R}$ & 30 & -90 & 2 & 49.0 & Middle occipital gyrus \\
\hline 5 & L & -34 & 56 & 6 & 48.4 & Dorsolateral prefrontal cortex \\
\hline 12 & $\mathrm{~L}$ & -24 & -32 & 68 & 48.0 & Sensorimotor cortex \\
\hline 17 & $\mathrm{R}$ & 6 & 52 & 26 & 48.0 & Superior medial frontal gyrus \\
\hline \multirow[t]{2}{*}{17} & $\mathrm{~L}$ & -26 & 8 & -36 & 46.9 & Temporal pole \\
\hline & & -28 & 2 & -30 & 46.6 & Superior temporal gyrus \\
\hline 5 & $\mathrm{R}$ & 46 & -6 & -42 & 46.4 & Inferior temporal lobe \\
\hline
\end{tabular}

left). We focused on this contrast because the previous results showed an increased weighting on health in both choices and the vmPFC value signals. We focused on this time window because it was identified by previous analyses as the period over which stimulus values were computed. Second, we used this map to forward-model the projected average time course for each ROI and subject, averaged across hemispheres (see Fig. $8 A$, middle). Third, we applied several preprocessing steps on the time-series, so that they satisfied the assumptions required by GCCA. Preprocessing included linear detrending, subtraction of the temporal mean, and division by the temporal SD. Data across subjects was combined into one matrix treating each subject as a single realization of an underlying stochastic process, followed by subtraction of the ensemble mean and division by the ensemble SD. First-order differencing was applied to address covariance nonstationary. Augmented Dickey-Fuller and KPSS tests produced divergent results, providing no clear evidence regarding covariance stationarity. Because additional differencing necessary for convergence would make interpretation difficult, we considered first-order differencing sufficient to approximate the stationarity assumptions required by Granger causality. These steps produced the matrix of sources and data points used in Granger causal modeling (see Fig. $8 A$, right). Fourth, we estimated the GCCA model among the ROIs over the $450-650 \mathrm{~ms}$ window. The optimal model order selected using the 
Bayesian information criterion was 10, corresponding to a lag of $20 \mathrm{~ms}$. Significance was assessed using a threshold of $p=0.01$, Bonferronicorrected. For all comparisons showing significant effects, the DurbinWatson test found no significant correlation of the residuals, and the consistency test showed high consistency of the fitted model with the correlation structure of the data $(>85 \%)$.

\section{Results}

Subjects participated in two separate EEG sessions, each consisting of three separate parts (Fig. 1). First, subjects were shown pictures of 200 different snack foods, one at a time, and had to provide tastiness and healthiness ratings for each of them using a four-point scale ( 1 = Strong-No, 2 = Weak-No, 3 = Weak-Yes, 4 = Strong-Yes). These ratings provide measures of subjects' perceptions of the level of these attributes for each food in each session, independent of the subsequent choices. Second, subjects were shown pictures of the same foods, one at a time, and had to decide whether or not they wanted to eat them at the end of the experiment. They entered their decisions using the same fourpoint scale, which allowed us to simultaneously measure their choice (yes/no) and the strength of their preferences (strong/ weak). Third, the choice made by the subject for a randomly selected food was implemented. See Materials and Methods for more details.

Critically, the two EEG sessions differed on the goals that subjects had when making the food choices. In the first session, which we refer to as the NC, subjects were asked to make food choices naturally. In the second condition, which we refer to as the SCC, subjects were given an incentive to exercise dietary selfcontrol when making their choices. In particular, they were weighed at the beginning of the SCC session and were told that if they lost $>0.25 \%$ of their body weight over the next week (up to a maximum of 1 pound), they would earn an additional $\$ 100$. The weight-loss intervention was not of direct experimental interest, and was used only to induce subjects to exercise selfcontrol reliably during the SCC choices. The order of the NC and SCC sessions was not counterbalanced because we were concerned that it might have a permanent impact on the choices made by subjects in the experiment. Although this design feature might have resulted in increased expertise and familiarity with the task during the SCC session, and thus more consistent decisions and faster responses, it did not contaminate the analyses described below (see Materials and Methods for details).

The analyses below are organized as follows. First, we analyzed the behavioral data, mainly with the goal of verifying that the weight-loss intervention was successful. Second, we used the ERP data to look for evidence of increased attentional filtering, early in the decision process, during successful self-control trials. Third, we used the ERP data to look for evidence of increased late value modulation during the SCC session, where subjects have an incentive to exercise self-control, in contrast to the NC session, where they do not.

\section{Behavior: choice responses}

We performed several analyses of the choice responses to verify that the weight-loss intervention increased self-control. First, as shown in Figure $2 A$, a comparison of behavior between the two conditions showed a significant shift from a majority of positive responses in the $\mathrm{NC}$ to a majority of negative responses in the SCC $\left(\chi^{2}=3755.7, p \approx 0\right)$. This is to be expected if individuals exercise self-control in large part by refusing tasty but unhealthy items, like candy or chips.

To investigate this further, we examined the effect of condition as a function of food type (Fig. 2B). In particular, we divided foods into four categories: disliked-unhealthy, disliked-healthy, liked-unhealthy, and liked-healthy. Note that self-control is required when individuals are shown liked-unhealthy or dislikedhealthy foods, but not in the other two cases. We found that in the SCC subjects were more likely to reject unhealthy foods (Liked Unhealthy: $t_{(27)}=11.1, p=1.5 \times 10^{-11}$; Disliked Unhealthy: $\left.t_{(27)}=4.83, p=4.9 \times 10^{-5}\right)$ and to accept healthy foods that they disliked $\left(t_{(27)}=-2.36, p=0.03\right)$. The effect was particularly large for the case of liked-unhealthy foods, like candy or chips, which again suggests that individuals exercised self-control in large part by refusing to eat these types of items.

Another way of looking at the extent to which individuals exercise self-control is to measure how their choices vary with the perceived health and taste attributes of the foods. To do this, we estimated a logistic regression of choice (yes/no) versus health and taste ratings, separately for each individual and condition, given the attribute ratings provided in each session. An increase in self-control involves an increase in the regression coefficient for the health rating and/or a decrease in the regression coefficient for taste. Figure $2 C, D$ shows that during the NC, subjects' choices relied almost exclusively on taste, whereas in the SCC their decisions incorporated information about taste and health (condition $\times$ rating interaction: $t_{(27)}=8.9, p=1.5 \times 10^{-9}$ ).

\section{Behavior: changes in attribute ratings}

The previous results show that individuals exercised self-control during the SCC both by increasing the weight that they gave to health, and by decreasing the weight that they gave to taste. However, subjects can also increase their self-control by changing their perception of the items (i.e., by viewing foods like candy as less healthy and tasty, and foods like broccoli as healthier and tastier), independently of how they are weighted. To investigate whether this additional self-control mechanism was at work, we computed mean taste and health ratings across foods for each individual and condition. As shown in Figure 2E, the ratings were very highly correlated across conditions (taste: Spearman $\rho=$ $0.85, p<10^{-8}$; health: Spearman $\rho=0.84, p<10^{-8}$ ). Yet the average ratings were nonetheless significantly lower in the SCC session, as seen by the number of points clustered below the line of unity, although the magnitude of the effect was small (taste: $t_{(27)}=3.19, p=0.004$; health: $t_{(27)}=2.4, p=0.03$ ). Together with the previous results, this suggests that both mechanisms of self-control were at work, but that the change in attribute weighting plays a more important role.

\section{Behavior: reaction times}

With regards to reaction times, the two conditions showed similar measures of central tendency and variability (NC: median = $861 \mathrm{~ms}, \mathrm{SD}=316$; SCC: median $=841 \mathrm{~ms}, \mathrm{SD}=313$ ), though differences in the skew of the two distributions were significant, reflecting a heavier right tail in the first $\mathrm{NC}$ session (NC: skew $=$ 1.64; SCC: skew $\left.=1.54 ; t_{(27)}=2.03, p=0.053\right)$. Likewise, the RTs for each decision type were similar across conditions (Fig. $2 F$ ), as shown by a two-way ANOVA (Condition $\times$ Decision), which revealed no significant main effect of session $(F<1)$. In contrast, the main effect of Decision was highly significant $\left(F_{(3,78)}=21.9\right.$, $\left.p=2.1 \times 10^{-10}\right)$, reflecting the inverted $U$-shaped function of median RT by Decision (quadratic contrast: $F_{(1,78)}=64.5, p=$ $\left.8.2 \times 10^{-12}\right)$. Additionally, the interaction of Condition $\times$ Decision was also significant $\left(F_{(3,78)}=8.9, p=3.7 \times 10^{-5}\right)$, due to the different skew in the distribution of reaction times between the NC and SCC conditions: whereas subjects were slowest to respond during Weak-No decisions in the NC, they shifted to longer reaction times during Weak-Yes in the SCC trials. 

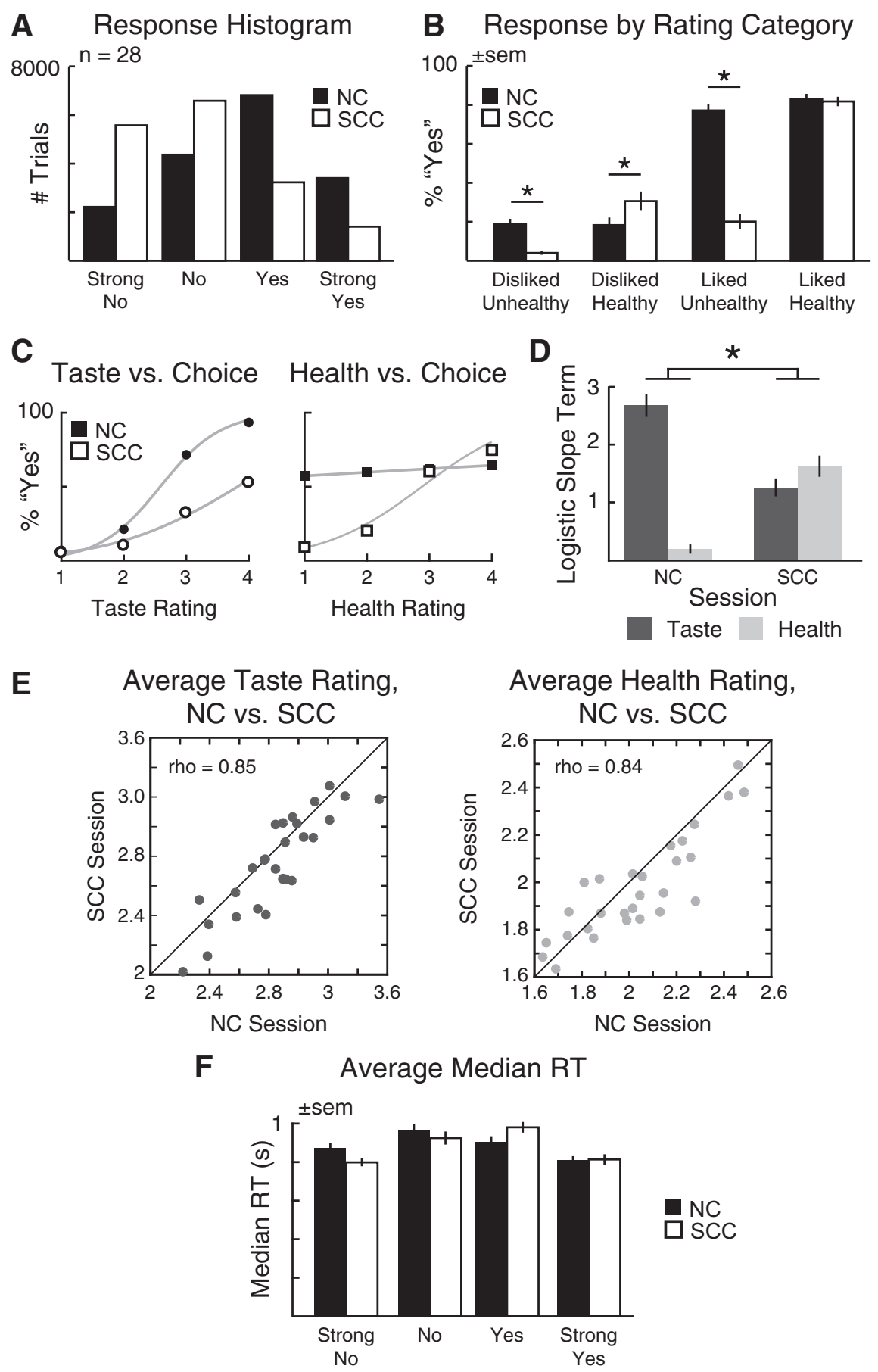

Figure 2. Behavioral data. $A$, Histogram of responses for $\mathrm{NC}$ and $\mathrm{SCC}$ conditions. $\boldsymbol{B}$, Responses for each session binned by rating category in terms of taste (liked or disliked) and health (healthy or unhealthy). C, Group average choices as a function of taste (left) and health (right) ratings. $\boldsymbol{D}$, Average slope terms for a logistic regression of choice (yes/no) on taste and health ratings, separately for each subject and condition. $E$, Correlation of average taste (left) and health (right) ratings for the NC and SCC sessions. Each point denotes the average for one subject across all foods; $45^{\circ}$ line is shown. $\boldsymbol{F}$, Average median RTs by session. All error bars reflect SEM. ${ }^{*} p<0.05$.

ERP and early attentional filtering: N1 responses and self-control We next performed three tests of the hypothesis that increased self-control involves deployment of top-down attentional filtering early in the decision period. The first test is based on the properties of the N1 response. The second test is based on the idea that, under top-down attentional modulation, there should be more prefrontal activation during successful self-control trials. The third test is based on expected changes in phase locking between occipital and frontal sensors.

First, consider the test associated with the N1 response. This response is associated with a negative deflection that occurs at occipital electrodes $\sim 150-200$ ms after stimulus onset, and is thought to reflect early stages of perceptual processing in extrastriate visual areas (Hopf et al., 2002). Importantly, the N1 amplitude increases with attention and working memory demands (Hillyard and Anllo-Vento, 1998; Rose et al., 2005; Zanto and Gazzaley, 2009), and is dramatically reduced in patients with prefrontal damage (Swick, 1998; Knight et al., 1999). This suggests the N1 response also reflects top-down inputs from frontal executive regions, and that it can be used as a marker of early top-down attentional filtering.

We hypothesized that, in our paradigm, attentional filtering would take the form of inhibition of early perceptual processing for potentially distracting, goal-irrelevant items, as part of a general attentional suppression when tempting foods may be present. The hypothesis can be tested as follows. Begin by dividing the trials of the SCC session into three types: (1) successful selfcontrol trials, in which subjects responded Yes to healthy but disliked foods, or No to liked but unhealthy foods; (2) failed selfcontrol trials, in which subjects responded No to healthy-disliked foods or Yes to likedunhealthy foods; and (3) no-control trials that did not require self-control, involving healthy-liked or unhealthy-disliked items. The hypothesis then predicts that the amplitude of the N1 response should be most negative in failed self-control trials and least negative in successful self-control trials, with no-control trials in between. Furthermore, because attentional filtering is only required when there is an incentive for selfcontrol, we hypothesized that this pattern would be present in the SCC, but not during the NC.

We performed the test in two steps. First, we verified that the N1 response was present in our dataset, regardless of the self-control condition. To do this, we computed the average ERP response over all occipital sensors, for SCC and NC trials separately. As shown in Figure $3 \mathrm{~A}$, we found a characteristic N1 $\sim 170$ ms poststimulus in both cases (NC: $M=176 \mathrm{~ms}$, $S D=11.6$; SCC: $M=176 \mathrm{~ms}, S D=13.3)$. Second, for every subject, trial type, and session we computed the mean amplitude between 150 and $200 \mathrm{~ms}$ poststimulus. We found a clear linear ordering of amplitudes (Fig. 3B) associated with self-control success, noncontrol, and self-control failure in the SCC, but not in the NC (Session $\times$ Condition interaction: $F_{(2,54)}=5.97, p=0.005$; main effects, n.s.). This was confirmed 
A

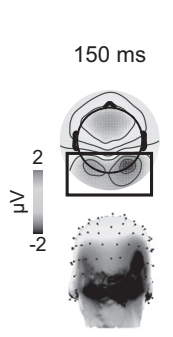

Grand Average Waveform, Occipital Sensors
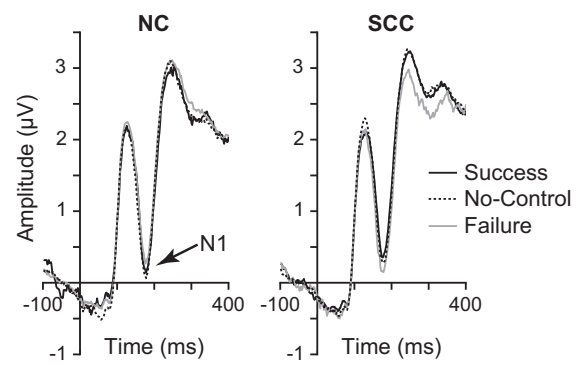

B

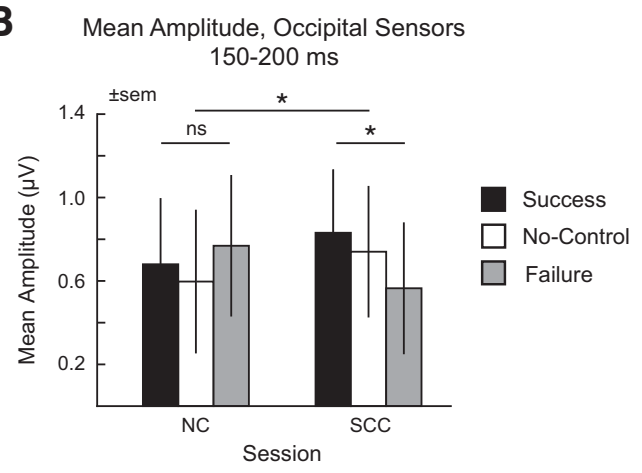

Figure 3. Analysis of $\mathrm{N} 1$ responses associated with attentional filtering. $\boldsymbol{A}$, Left, Scalp distribution of evoked potentials at $150 \mathrm{~ms}$, revealing strong responses over occipital sensors (black box). Right, Grand average waveforms at occipital sensors for self-control success (black), noncontrol (dashed), and self-control failure (gray) in $\mathrm{NC}$ and SCC sessions, displaying the visual $\mathrm{N} 1$ deflection at $\sim 170$ ms poststimulus onset. $\boldsymbol{B}$, Mean evoked amplitude $(\mu \mathrm{V})$ for self-control success (black), noncontrol (white), and self-control failure (gray) at occipital sensors from 150 to $200 \mathrm{~ms}$ in the $\mathrm{NC}$ versus $\mathrm{SCC}$ session. Error bars reflect SEM. ${ }^{*} p<0.05$.

by a significant linear contrast for the SCC $\left(F_{(1,54)}=10.3, p=\right.$ $0.002)$, but not for the NC $\left(F_{(1,54)}=1.14, p=0.29\right)$.

ERP and early attentional filtering: stronger dlPFC activity during successful self-control

Next, we hypothesized that increased top-down attentional modulation would be associated with stronger dIPFC activity early on during successful self-control trials, as compared with failed selfcontrol trials. The hypothesis is based on previous studies, which have shown dynamic fluctuations in top-down attentional filtering by dlPFC during perceptual and working memory tasks (Zanto and Gazzaley, 2009; Lennert and Martinez-Trujillo, 2011; Suzuki and Gottlieb, 2013).

We tested this hypothesis in two steps. First, we used twotailed paired $t$ tests to compare the responses in each sensor between successful and failed self-control trials, using $50 \mathrm{~ms}$ windows, from 100 to $1000 \mathrm{~ms}$ after stimulus onset. We corrected for multiple comparisons using permutation tests. As shown in Figure $4 A$, we found multiple sensors and time windows at which the responses in successful self-control trials were significantly different from those in failed self-control trials. The earliest differential response occurred from 150 to $200 \mathrm{~ms}$ in frontal and occipital sensors. Second, we used distributed Bayesian source reconstruction (Friston et al., 2008; Litvak and Friston, 2008) to localize, separately, cortical regions associated with significant responses during successful and failed self-control trials. We then used a "difference of localizations" approach (Henson et al., 2007), to identify regions that exhibited a stronger response in successful than failed self-control trials. In this approach, separate localizations are performed for the two conditions of interest, and then the two localizations are contrasted statistically. In

\section{A Self-Control Success vs. Failure, SCC}

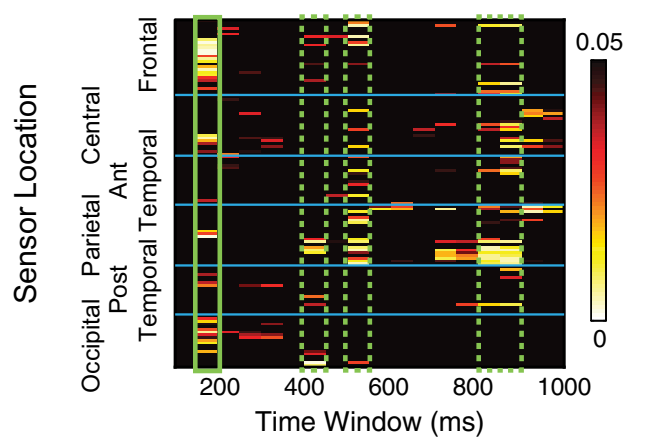

B

$$
\begin{aligned}
& \text { Localization, Success vs. Failure, } \\
& \qquad 150-200 \mathrm{~ms}
\end{aligned}
$$
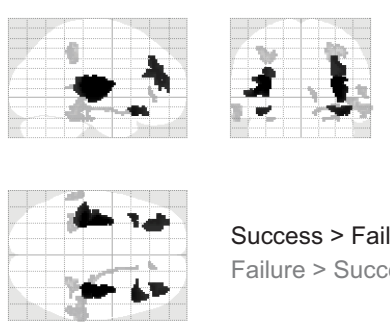

Success $>$ Failure

Failure $>$ Success

FWE $p=0.01$

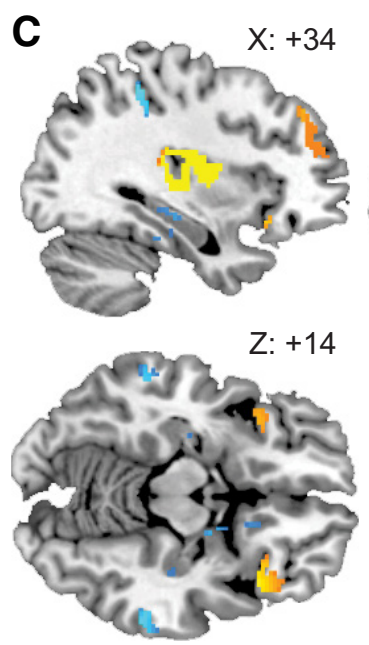

$\mathrm{Y}:+42$
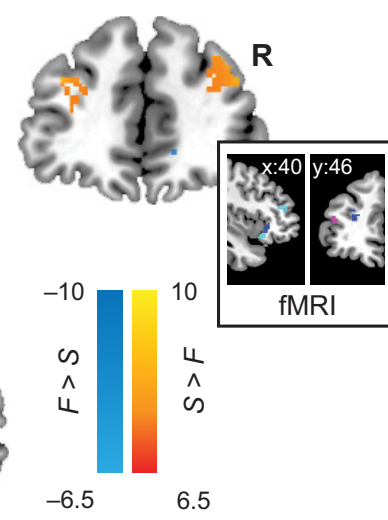

T Value

Figure 4. Analysis of self-control success versus failure. $A$, Heat map showing significant activity for self-control success (yes to healthy disliked, no to unhealthy liked) versus failure. Significant effects were visible at multiple time windows including $400-450,550-600$, and $800-900 \mathrm{~ms}$ (dashed green boxes). However, only in the first $150-200 \mathrm{~ms}$ window (solid green box) did source localizations reach the stringent significance threshold of FWE-corrected $p=$ 0.01. B, "Glass brain" display depicting MIP of source reconstructions from 150 to $200 \mathrm{~ms}$ for Success $>$ Failure (black) and Failure $>$ Success (gray), FWE-corrected $p<0.01$. C, Sources overlaid on representative brain images (warm colors, Success $>$ Failure; cool colors, Failure $>$ Success). Inset, Spherical masks based on peak coordinates from $3 \mathrm{fMRl}$ studies [blue, Kober et al. (2010); magenta, Hare et al. (2009); cyan, McClure et al. (2004)], 6 mm radius.

particular, we compared the separate source reconstructions for self-control success and failure trials over the $150-200$ ms poststimulus interval using paired $t$ tests (Fig. $4 B$ ). We found stronger responses in bilateral dlPFC, vlPFC, and insula during successful self-control trials (Fig. 4C; Table 1). In contrast, stronger responses were observed in inferior parietal lobe, middle and superior temporal gyri, and hippocampal and parahippocampal cortex during failed self-control trials. Interestingly, despite the coarse spatial resolution of the source reconstruction technique, 
A

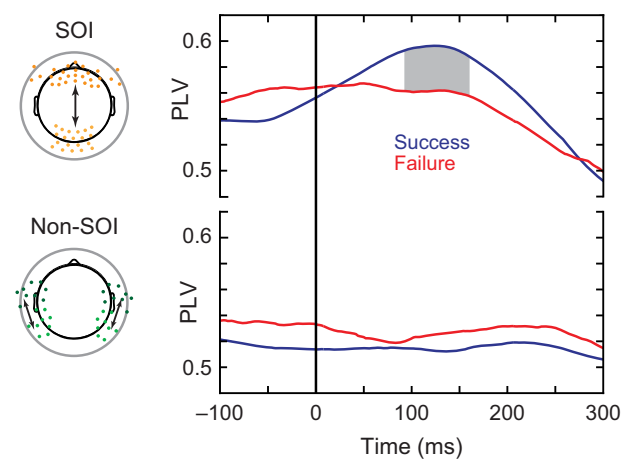

B

Mean Anterior-Posterior PLV, 100 to 150 ms Post-Stimulus

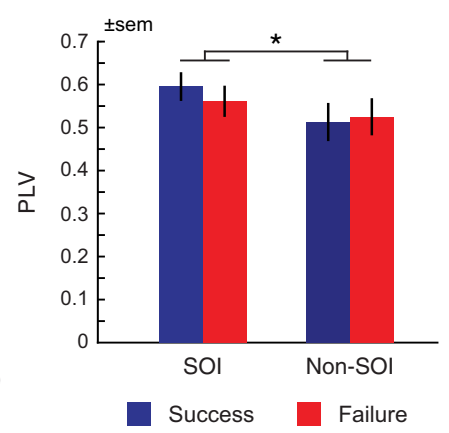

Figure 5. Phase-locking value analysis. $\boldsymbol{A}$, Phase-locking values, alpha band $(8-12 \mathrm{~Hz})$. Left: Sensor positions of frontal and occipital SOIs (orange) and control non-SOI sensors (green). Right, PLV from - 100 to $300 \mathrm{~ms}$ after stimulus onset for self-control success (blue) and failure (red). Gray shading denotes significant differences surviving permutation correction. $\boldsymbol{B}$, Comparison of mean anterior-posterior PLV for frontal-occipital SOIs versus control non-SOI sensors, $100-150$ ms after stimulus onset. Error bars reflect SEM. ${ }^{*} p \leq 0.05$.

the dlPFC sources identified in the Success $>$ Failure comparison match previous fMRI results (Fig. $4 C$, inset) for self-control in dieters (Hare et al., 2009), intertemporal choice (McClure et al., 2004), and regulation of craving in smokers (Kober et al., 2010).

\section{ERP and early attentional filtering: PLV between frontal and occipital sensors}

The final test of early attentional filtering involved looking for differences in PLV (Lachaux et al., 1999) between frontal and occipital sensors during successful self-control, particularly in the alpha band $(8-12 \mathrm{~Hz})$. Previous studies suggest that long-range synchronization between frontal and occipital sensors is a plausible mechanism for top-down attentional filtering (Zanto et al., 2010, 2011). Importantly, the hypothesized change in phase coherence is expected to occur before the onset of the N1-evoked potentials: for example, increased PLV associated with attentional control has been reported between 15 and $130 \mathrm{~ms}$ after stimulus onset (Zanto et al., 2010). Although this time window partially overlaps with the visual P1 component, alpha phase modulation did not significantly correlate with attentional modulation, in line with previous work suggesting partial independence of event-related responses and PLV (Thut et al., 2003). Instead, it is likely that PLV reflects anticipatory gating by the frontoparietal attention network.

To test this hypothesis, we computed alpha-band PLV between frontal and occipital SOIs defined a priori based on scalp location (Fig. 5A, left). PLVs were computed for the window from $100 \mathrm{~ms}$ pre- to $300 \mathrm{~ms}$ poststimulus onset, with special interest in the time window preceding the onset of the N1 response $(\sim 150-200 \mathrm{~ms})$. Failures of self-control were associated with significantly lower PLVs between frontal and occipital SOIs relative to self-control successes, with the significance of permutation-corrected paired $t$ tests peaking between 98 and 160 $\mathrm{ms}$ after stimulus onset (Fig. 5A, top right). As a control, we performed a similar PLV analysis between sets of "non-SOI" sensors, based on a priori definitions for anterior frontotemporal versus posterior occipitotemporal electrodes. During the same time window of interest, these sensor sets did not show any significant difference between successful versus failed self-control (Fig. 5A, bottom right). Confirming this pattern (Fig. 5B), the difference between self-control success and failure in SOI versus non-SOI electrodes was significant in the $100-150 \mathrm{~ms}$ window, as measured by a paired $t$ test $\left(t_{(27)}=2.1, p=0.045\right)$.
Given the latency of the PLV differences, one potential concern is that they could be driven by ERP modulation of the P1. However, in line with Zanto et al. (2010), we found no significant difference between ERP responses to successful and failed self-control in the time preceding the N1. Thus, our results are consistent with previous reports of the partial independence of ERP and PLV measures (Thut et al., 2003).

Because estimates of PLV are inflated when the number of trials is low, the unequal numbers of trials in the self-control success versus failure conditions presents another cause for concern. However, this asymmetry is unlikely to explain our results, as the small number of self-control failures would create bias in the opposite direction to our findings. Consistent with this idea, weighting the average PLV computation by the number of trials per individual produced an even more marked visual separation (unreported) between the success and failure conditions.

Together, these results support the hypothesis that increased self-control involves early attentional filtering, implemented via increased synchronization between activity in frontal and posterior regions. This pattern may reflect dynamic fluctuations in top-down attentional filtering by dIPFC, in keeping with its role in ignoring irrelevant stimuli during perceptual and working memory tasks (Zanto and Gazzaley, 2009; Lennert and MartinezTrujillo, 2011; Suzuki and Gottlieb, 2013). Consistent with this idea, a post hoc analysis showed that reaction times were significantly slower for failed than for successful self-control trials $\left(t_{(27)}=\right.$ $-3.6, p=0.002)$, perhaps reflecting increased influence of distracting information on decision-making in these trials.

\section{ERP evidence for late value modulation: stimulus value signals in $v m P F C$}

Next, we performed three separate tests of the hypothesis that self-control involves late modulation of stimulus value signals in vmPFC, by increasing the extent to which values are responsive to health attributes and/or decreasing the extent to which they are responsive to taste attributes. The first test verified that the same regions of vmPFC encoded stimulus values during the $\mathrm{NC}$ and SCC session. The second test is based on the idea that the extent to which the taste attribute is represented in the value signals should decrease between the NC and the SCC, and/or that the opposite should be true for the health attribute. The third test looked for evidence of modulation of vmPFC by dIPFC at the later stages of the decision trial using a Granger causality analysis.

Consider the first test, which asked whether there is a common region of vmPFC that encoded stimulus values during the NC and SCC sessions. This test is important because previous fMRI (Yang et al., 2003; Kable and Glimcher, 2007; Knutson et al., 2007; Tom et al., 2007; Hare et al., 2008, 2009, 2010; Boorman et al., 2009; Chib et al., 2009; FitzGerald et al., 2009; Basten et al., 2010; Philiastides et al., 2010; Plassmann et al., 2010; Wunderlich et al., 2010; Litt et al., 2011), EEG (Harris et al., 2011), and MEG (Hunt et al., 2012) studies have found that a common region of vmPFC encodes stimulus values across a wide class of paradigms, and regardless of the level of self-control deployed by the subjects 
A

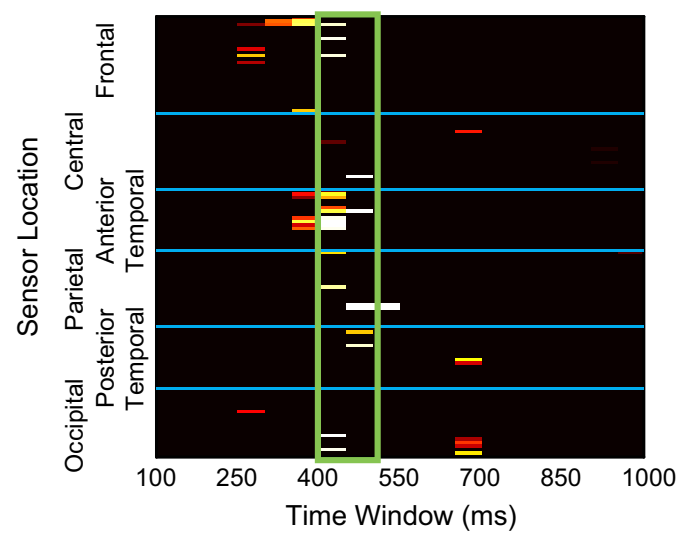

C

NC, 400 to 500 ms post-stimulus

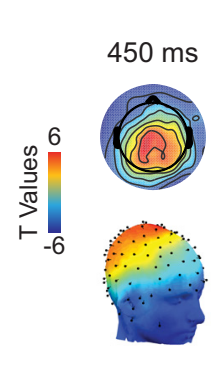

B P Values, Stimulus Value Beta, SCC

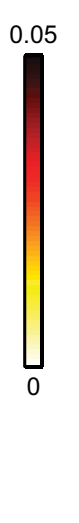

D

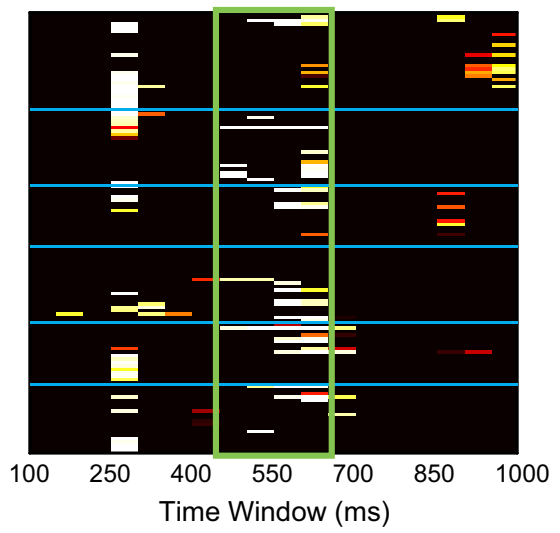

SCC, 450 to 650 ms post-stimulus

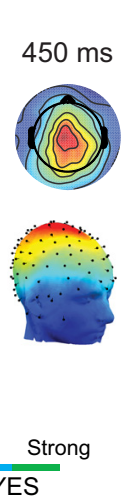

$\mathbf{E}$
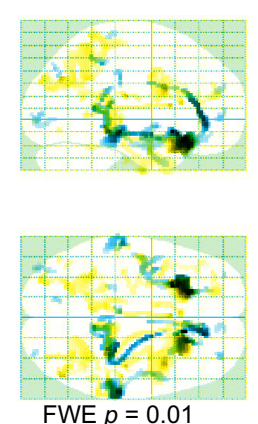

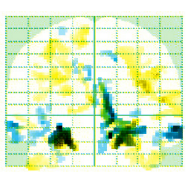

$\mathrm{NC}, 400-500 \mathrm{~ms}$

SCC, $450-650 \mathrm{~ms}$
$\mathbf{F}$

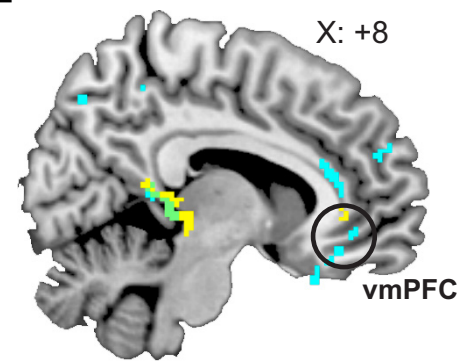

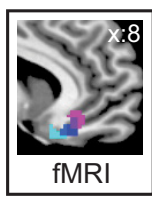

Figure 6. Analysis of stimulus value. Top, Heat maps of significant $p$ values associated with stimulus value in $(\boldsymbol{A}) \mathrm{NC}$ and $(\boldsymbol{B}) \mathrm{SCC}$ sessions. Both sessions show significant stimulus value activity arising from $\sim 400-450 \mathrm{~ms}$ after stimulus onset (green boxes). Middle, Topographic scalp distribution (left) and average waveforms (right) for (C) $400-500 \mathrm{~ms} \mathrm{period} \mathrm{in} \mathrm{NC,} \mathrm{and} \mathrm{(D)} 450-650 \mathrm{~ms}$ period in SCC. For all average waveforms, the highlighted gray window indicates the window of significant activity, which was also specified as the time window of interest for source reconstruction. Red, Strong No; orange, No; cyan, Yes; green, Strong Yes. E, Source reconstruction results for NC (yellow) and SCC (cyan, $450-650$ ms) sessions displayed on a glass brain MIP.F, Sources overlaid on a representative brain image show localization to regions including vmPFC (circled). Inset, Spherical masks based on peak coordinates from three fMRI studies [blue, Plassmann et al. (2007); magenta, Hare et al. (2009); cyan, Litt et al. (2010)], 6 mm radius.

(Kable and Glimcher, 2007; Hare et al., 2009, 2011; Hutcherson et al., 2012).

We tested for this hypothesis in two steps. First, we estimated a linear regression, across $50 \mathrm{~ms}$ bins, from 100 to $1000 \mathrm{~ms}$ after stimulus onset, of each subject's evoked activity versus the decision made in each trial ( $1=$ Strong-No to $4=$ Strong-Yes $)$. The resulting maps of estimated coefficients (i.e., beta maps) were then aggregated across subjects using one-sample $t$ tests for each sensor and time window. Results were corrected for multiple comparisons using exact permutation tests. We found significant activity related to stimulus values beginning at 400-450 ms after stimulus onset, for both the NC and the SCC, distributed over central and frontotemporal sensors (Fig. 6A,B). Grand average waveforms, computed from sensors-of-interest with significant stimulus value activity at $p \leq 0.05$, showed a clear separation of activity by stimulus value during this time window, with the linear effect reaching corrected significance from 400 to $500 \mathrm{~ms}$ in the NC, and from 450 to $650 \mathrm{~ms}$ in the SCC (Fig. 6C,D, gray boxes). Furthermore, we found no significant differences in the coding of stimulus values between the NC and SCC during the $400-650$ ms window $\left(t_{(27)}=0.02, p=0.99\right)$.

Second, we performed a Bayesian source reconstruction to localize the stimulus value signals to specific brain regions. Figure $6 E$ and Tables 2 and 3 describe the resulting maximum intensity 


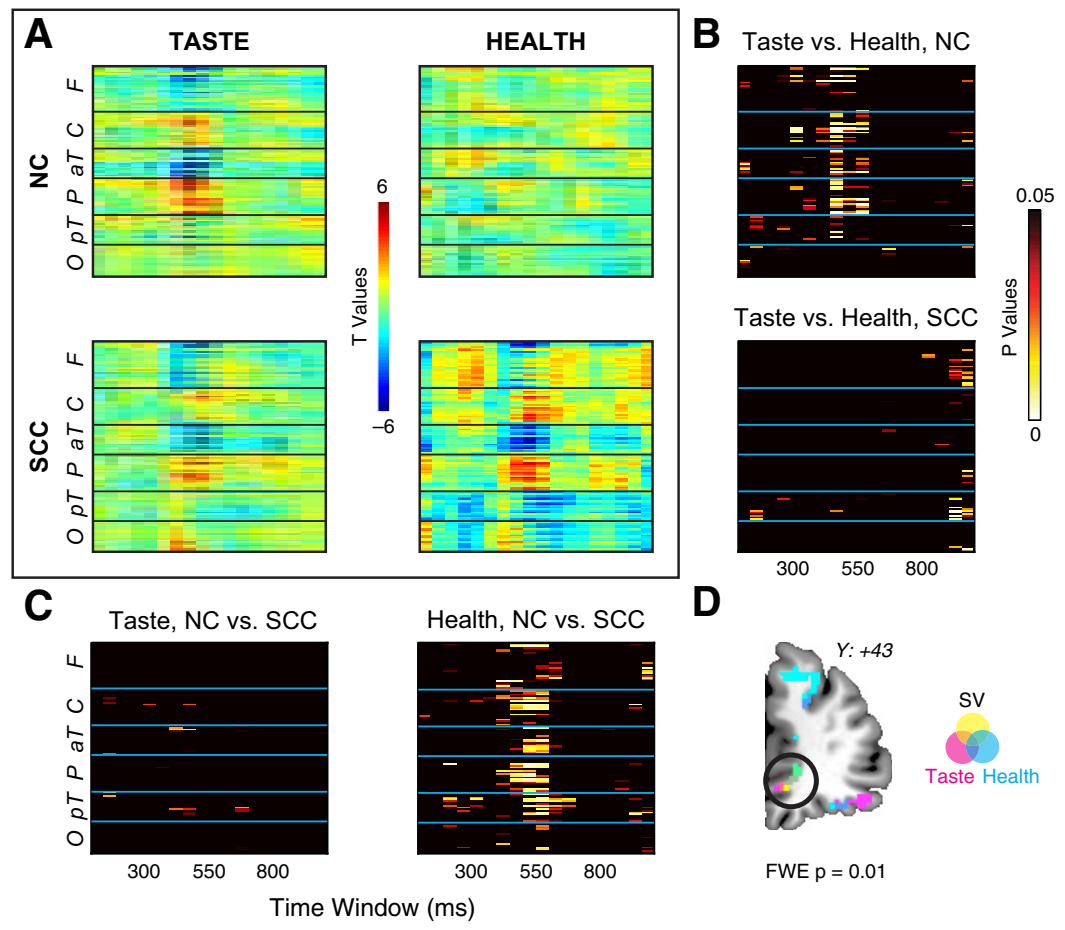

Figure 7. Weightings of ERP data on taste and health. $A$, Heat maps of $t$ values from one-sample t tests on taste (left) and health (right) betas across subjects, in NC (top) and SCC (bottom) sessions. B, Statistical significance maps comparing taste versus health in NC (top) and SCC (bottom) sessions. C, Statistical significance maps comparing NC versus SCC session for taste (left) and health (right). D, Source reconstruction of neural data showing significant weighting on the linear ordering of stimulus value (yellow), tastiness (magneta), and healthiness (magenta). Overlapping source reconstructions are indicated by the color overlays in the key (orange $=$ stimulus value + taste; blue $=$ taste + health; green $=$ stimulus value + health; gray $=$ stimulus value + taste + health).

projections. Stimulus value activity was consistently localized to vmPFC (Fig. $6 F$ ), in both the NC and SCC conditions. Interestingly, and despite the limited precision of source reconstruction methods, the localized signals in vmPFC closely resembled those from previous fMRI and EEG results (Fig. $6 F$, inset).

ERP evidence for late value modulation: differential representation of health and taste attributes during SCC trials

Next, we hypothesized that late value modulation during the SCC, compared with the NC, would be associated with a decreased representation of taste attributes and/or an increased representation of health attributes, especially in frontal sensors related to the vmPFC stimulus value signals.

To test this hypothesis, we examined how activity throughout the brain correlated with the tastiness and healthiness of the foods, particularly in frontal sensors of interest associated with stimulus valuation. In particular, we estimated another linear regression, with similar bins and time windows as the previous one, of each subject's evoked activity versus the taste and health ratings provided for each food in that condition. As before, beta maps were then aggregated across subjects using one-sample $t$ tests for each sensor and time window, and compared using paired $t$ tests corrected by permutation testing.

Consistent with the behavioral data, we found that ERP responses showed widespread greater weighting on taste than health in NC, but not in SCC (Fig. $7 A, B$ ). We also found that the ERP weighting on health at central and frontotemporal sensors increased significantly from the NC to the SCC session after 450 ms poststimulus onset, but only minor differences were found for taste weighting between the two conditions (Fig. 7C). Interestingly, and consistent with the hypothesis, the beta map for in- creases in health weights resembles the time course and sensor map for stimulus value computations. In addition, a Bayesian source reconstruction of the taste and health signals showed vmPFC sources largely overlapping with the region identified above for stimulus valuation (Fig. $7 D$ ). More concretely, a comparison of responses in the sensors reflecting stimulus value related activity in both the NC and SCC revealed larger estimated coefficients for taste than health in the $\mathrm{NC}\left(t_{(27)}=4.4\right.$, $\left.p=1.6 \times 10^{-4}\right)$, but not in the SCC. We also found larger estimated coefficients for health in the SCC versus NC $\left(t_{(27)}=\right.$ $-3.4, p=0.0022)$, but not for taste.

ERP evidence for late value modulation: Granger causality analysis

The final test for the hypothesis of late value modulation involved looking for directed connectivity from dIPFC to the vmPFC at the time that stimulus values are computed. This hypothesis was motivated by previous fMRI work from our group (Hare et al., 2009, 2011), which found that successful self-control is associated with increased functional connectivity between dIPFC and the vmPFC valuation region. Note, however, that due to the limitations of the BOLD data, our previous work was not able to test for the directionality of the connectivity, or its timing within a decision period.

We tested this hypothesis by carrying out a GCCA (Seth, 2010; Bressler and Seth, 2011) among several ROIs in the SCC session, looking at the $450-650 \mathrm{~ms}$ window during which stimulus values are computed. GCCA is useful in this context because it allows us to look for directional interactions between time courses of neural activity. In particular, for two simultaneously measured timevarying signals $X$ and $Y$, signal $X$ is considered Granger causal if past information about $X$ improves the prediction of signal $Y$, over what can be predicted using only lagged values of $Y$.

Because we found differential effects of successful over failed self-control at multiple time periods (including $150-200 \mathrm{~ms}$, $400-450 \mathrm{~ms}$, and $500-550 \mathrm{~ms}$; Fig. $4 A$ ), we applied the GCCA to ROIs associated with self-control across all of these periods. To be inclusive, we characterized the ROIs using a conjunction analysis with a liberal threshold of $p<0.005$ (uncorrected), for the contrast of successful $>$ failed self-control trials, which identified regions of dlPFC, insula, and inferior frontal gyrus shown in Figure $8 B$. Additionally, a vmPFC ROI was derived from the conjunction of stimulus value localization at $250-350 \mathrm{~ms}$ and $450-650 \mathrm{~ms}$ after stimulus onset, which covers the entire period over which activity in frontal sensors correlated with stimulus values.

The GCC analysis among these areas proceeded in several steps, all of them applied to data for the SCC only. First, we performed a Bayesian source reconstruction of the linear contrast for health ratings (least to most healthy) to generate a dipole intensity map for each subject (Fig. 8A, left). We focused on this contrast because the previous results showed an increased weighting on health in both choices and the vmPFC value signals. 


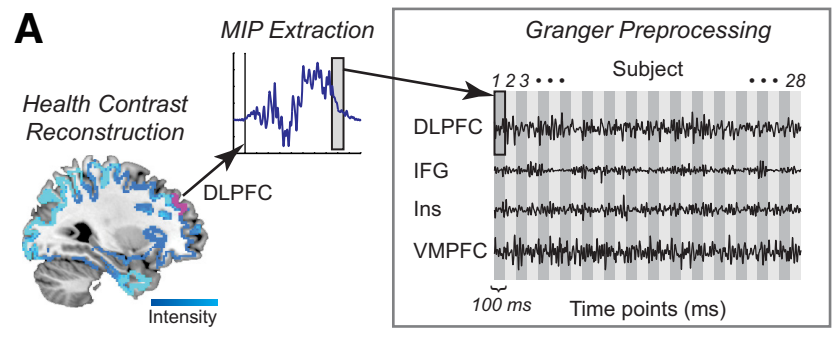

B

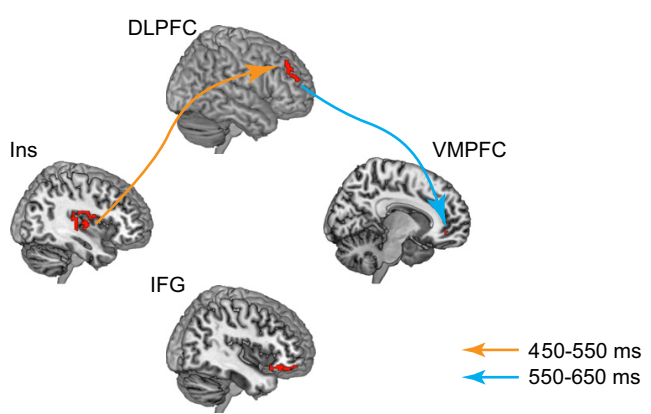

Figure 8. Exploratory Granger causal connectivity analysis. Note that due to the coarse spatial resolution of the source reconstruction technique, the selected ROIs are not precise anatomical regions but rather represent broad divisions of cortex. $\boldsymbol{A}$, Granger causal connectivity methodology. The linear response to healthiness (least to most healthy) was used as a surrogate for self-control. Left, Source reconstruction of the healthiness signal produced an intensity map for the modeled dipolar patches within each subject (shades of blue). Pink, dIPFC ROI from self-control success $>$ failure. Middle, Time courses of the MIP for each dipole in each ROI were extracted and averaged, then selected for specified time windows (gray box). Right, For each ROI, data for each time window were concatenated across subjects and preprocessed (linear detrending, subtraction of temporal mean, subtraction of ensemble mean, first-order differencing) before being entered into Granger causal modeling. $\boldsymbol{B}$, Model and causal connectivity for health contrast $450-650 \mathrm{~ms}$ after stimulus onset. All displayed connections are significant at a threshold of $p=0.01$, Bonferroni-corrected.

Second, we used this map to forward-model the projected average time course for each ROI and subject, averaged across hemispheres (Fig. 8A, middle). The resulting time courses are called MIPs. Third, after applying some preprocessing to the time courses, so that they satisfy the required assumptions (Fig. $8 \mathrm{~A}$, right), we performed a GCC analysis among the ROIs over the 450-650 ms window (see Materials and Methods for details).

We found no significant Granger causal connections between the ROIs at a Bonferroni-corrected threshold of $p=0.01$, over the entire 450-650 ms window. However, an analysis that allowed for differential connectivity during the 450-550 and the $550-650 \mathrm{~ms}$ windows found significant results. In particular, as shown in Figure $8 B$, we found significant connectivity from insula to dlPFC during the 450-550 ms window, and from dlPFC to vmPFC during the 550-650 ms window. A further post hoc check revealed that the dlPFC to vmPFC connectivity also remained significant when the start of the later window was moved to $500 \mathrm{~ms}$.

Together, the last three results provide evidence for the hypothesis that self-control involves modulation from dlPFC to vmPFC, starting $\sim 550 \mathrm{~ms}$ after stimulus onset, that increases the weighting of stimulus value signals in vmPFC on the healthiness of the foods.

\section{Discussion}

Although self-control is important for optimal decision-making, it can often be achieved in different ways. Here, in the context of a dietary choice task, we explored the neural bases of two different possible mechanisms for self-control: attentional filtering of early sensory input and later modulation of stimulus value signals computed in vmPFC. By comparing ERP activity when participants were incentivized to make choices naturally or with the goal of losing weight, we investigated the extent to which both mechanisms are activated with and without self-control.

Subjects showed clear changes in their choice behavior from the natural to self-control condition, shifting from almost exclusive reliance on taste attributes to similar weightings on taste and health. These behavioral adjustments were accompanied by changes in neural markers, measured both between the two experimental conditions, and across trials within the self-control condition, suggesting that multiple regions are involved in the successful deployment of self-control.

In line with previous work that has shown attentional modulation of early perceptual components (Rose et al., 2005; Zanto and Gazzaley, 2009), we found differential ERP activity for selfcontrol success versus failure as early as $150-200 \mathrm{~ms}$, associated with the visual N1 response. Joining a growing body of work on mind-wandering and fluctuations in attention (Smallwood and Schooler, 2006; Weissman et al., 2006; Cohen and Maunsell, 2011), the dynamic variations in N1 amplitude suggest that early differences in attentional modulation can be associated with farreaching behavioral effects.

Where does the effect of attentional filtering on self-control originate? Contrasting source reconstructions for self-control success greater than failure revealed a bilateral network of regions including the dlPFC, insula, and vlPFC. Although the extremely coarse spatial precision of the localization technique limits our inferences, these results agree with an extensive literature on cognitive and emotional regulation. In particular, our dlPFC source is very close to those found in previous fMRI studies of selfcontrol (McClure et al., 2007; Hare et al., 2009; Kober et al., 2010). In addition, the same area of vlPFC identified here has been linked to adjustments of behavior in the face of contextual changes (Mitchell, 2011).

Most intriguingly, the source localization of dlPFC, in conjunction with the reduced N1 response during successful selfcontrol, matches recent work suggesting a special role for this region in attention suppression (Lennert and Martinez-Trujillo, 2011; Suzuki and Gottlieb, 2013). In this light, the reduced N1 response associated with self-control success, relative to failure, may reflect anticipatory suppression in the presence of potentially tempting foods. At first sight, this interpretation runs counter to a previous finding in patients with prefrontal damage, who showed reductions in $\mathrm{N} 1$ amplitude compared with matched controls (Swick, 1998). However, it is important to note that this previous experiment was designed to look for neural correlates of attentional enhancement, whereas successful self-control in our task involves attentional filtering. In fact, when inhibition of taskirrelevant information is required, prefrontal patients actually show an increase in early sensory evoked potentials, relative to healthy controls (Knight et al., 1999). Our results highlight the importance of dlPFC for guiding behavior not only through enhancement of goal-relevant information, but also by suppression of potential distractors.

One proposed mechanism for top-down attentional filtering is via long-range synchronization in the alpha band $(8-12 \mathrm{~Hz})$. Consistent with other work showing increased early phaselocking between anterior and posterior regions for attended items (Zanto et al., 2010), successful self-control was associated with greater PLV between frontal and occipital sensors preceding the attentional modulation of the N1 response. Although our 
data cannot determine the direction of this modulation, previous work using transcranial magnetic stimulation strongly implicates prefrontal cortices in top-down changes in PLV (Zanto et al., 2011). With a latency overlapping the earliest cortical visual responses, this phase-coherence modulation does not appear to be stimulus-specific, instead reflecting a more general attention gating. In conjunction with the reduced N1 amplitude, this result points to heightened frontal-occipital synchrony as reflecting a broad suppression of early visual processing. Given that our task demanded continuous self-control over an extended period of time, such early perceptual dampening may form a first-line strategy for successful maintenance of contextual goals.

Aside from early attentional filtering, another possible route for self-control entails shifting the value assigned to specific perceptual attributes, such as taste or health. ERP activity in the time range associated with stimulus value computations, $\sim 450-650$ $\mathrm{ms}$ after stimulus onset, demonstrated just such a shift in health weightings at spatially overlapping sensors, and both stimulus value and taste and health value signals were localized to vmPFC. Although ERP correlates of energetic value (fat content) have been reported as early as $165 \mathrm{~ms}$ after stimulus onset (Toepel et al., 2009), our data suggest that valuation of taste and health attributes occurs relatively late, beyond the window of early perceptual processing.

Our findings therefore raise the question, suggested by previous neuroimaging (Hare et al., 2009, 2011) and rTMS (Camus et al., 2009; Cho and Strafella, 2009; Baumgartner et al., 2011) studies, of whether dIPFC can modulate vmPFC stimulus value computations during self-control. To test this idea, we examined the functional connectivity between these regions during the window of stimulus value computation via Granger causality. Although analysis of the larger time period from 450 to $650 \mathrm{~ms}$ failed to find any causal connections, further subdivision of the time course revealed significant causal connectivity from dlPFC to vmPFC from 500 to $650 \mathrm{~ms}$. Although the precise nature of this later top-down modulation remains unclear, these results join several recent studies demonstrating that dIPFC plays a causal role in decision-making (Camus et al., 2009; Cho and Strafella, 2009; Figner et al., 2010; Baumgartner et al., 2011; Philiastides et al., 2011).

We emphasize that although Granger connectivity is not sufficient to establish full causality, our data complement these findings by providing high-resolution information about when self-control modulations occur over the time course of choice. In pointing to the existence of multiple neural mechanisms by which dlPFC can affect behavior, our results also help to unify the decision-making literature with similar findings from attention and working memory (Zanto et al., 2011), suggesting various routes by which this region may influence behavior to reflect contextual goals.

Together, our results suggest that self-control during a simple choice task involves a combination of both early attentional filtering and late value signal modulation. This result mirrors a trend in conceptualizing self-control, epitomized by frameworks such as the dual mechanisms of control (DMC) account (Braver, 2012). Emphasizing the intrinsic variability of cognitive control, DMC posits the existence of two different modes of control, proactive and reactive, associated with different brain networks. Whereas proactive control reflects sustained, anticipatory activity in lateral prefrontal cortex, reactive control is asserted in a bottom-up fashion at the time of choice, arising transiently from stimulus-driven interference or episodic associations. Despite obvious parallels to this theoretical framework, especially in terms of proactive control, our data diverge from the DMC account in certain respects. For example, although the results of our Granger causal modeling are consistent with vmPFC value modulation as a "late correction" mechanism, the lack of interference measures in our experiment complicates any attempt to link this finding to reactive control.

Models of cognitive control often assume that the same brain networks underlie many different types of regulation. Supporting this idea, dlPFC has been identified repeatedly as a locus of cognitive control across dramatically different self-control tasks, including dieting (Hare et al., 2009), regulation of cigarette craving (Kober et al., 2010), and intertemporal choice (McClure et al., 2004). Our localization of dlPFC activity in the vicinity of these previous findings further points to the general importance of this region in a variety of situations requiring cognitive control.

In contrast to many fMRI studies of self-control, we also found highly significant neural generators localized to mid- to posterior insular cortex, a region associated with integration of interoceptive sensations such as temperature, pain, and sensual touch (Craig, 2002; Deen et al., 2011). Although this localization could reflect state-dependent interoceptive processing specific to dietary choice, recent work suggests this region encodes more complex concepts, such as objective inequality in the ultimatum game (Hsu et al., 2008; Wright et al., 2011) and reward prediction in intertemporal choice (Tanaka et al., 2004). It is also linked with dlPFC, and through its connections to anterior insula, with orbitofrontal cortex (Carmichael and Price, 1996; Craig, 2002; Singer et al., 2009), potentially allowing interactions between these regions during value computation. The connectivity between dIPFC and insula in our Granger causality analysis suggests that further research on the links between these regions is clearly warranted.

Collectively, these data provide novel insights into the neurocomputational processes of self-control, as well as their temporal dynamics. Further research examining more complex decision scenarios and/or clinical issues, such as obesity and addiction, could have broad ramifications for both real-world applications and our basic understanding of the many mechanisms by which self-control is implemented in the brain.

\section{References}

Basten U, Biele G, Heekeren HR, Fiebach CJ (2010) How the brain integrates costs and benefits during decision making. Proc Natl Acad Sci U S A 107:21767-21772. CrossRef Medline

Baumgartner T, Knoch D, Hotz P, Eisenegger C, Fehr E (2011) Dorsolateral and ventromedial prefrontal cortex orchestrate normative choice. Nat Neurosci 14:1468-1474. CrossRef Medline

Belouchrani A, Abed-Meraim K, Cardoso JF, Moulines E (1997) A blind source separation technique using second-order statistics. IEEE Trans Signal Proc 45:434-444. CrossRef

Boorman ED, Behrens TE, Woolrich MW, Rushworth MF (2009) How green is the grass on the other side? Frontopolar cortex and the evidence in favor of alternative courses of action. Neuron 62:733-743. CrossRef Medline

Braver TS (2012) The variable nature of cognitive control: a dual mechanisms framework. Trends Cogn Sci 16:106-113. CrossRef Medline

Bressler SL, Seth AK (2011) Wiener-granger causality: a well established methodology. Neuroimage 58:323-329. CrossRef Medline

Buschman TJ, Miller EK (2007) Top-down versus bottom-up control of attention in the prefrontal and posterior parietal cortices. Science 315: 1860-1862. CrossRef Medline

Camus M, Halelamien N, Plassmann H, Shimojo S, O’Doherty J, Camerer C, Rangel A (2009) Repetitive transcranial magnetic stimulation over the right dorsolateral prefrontal cortex decreases valuations during food choices. Eur J Neurosci 30:1980-1988. CrossRef Medline

Carmichael ST, Price JL (1996) Connectional networks within the orbital 
and medial prefrontal cortex of macaque monkeys. J Comp Neurol 371: 179-207. CrossRef Medline

Chib VS, Rangel A, Shimojo S, O'Doherty JP (2009) Evidence for a common representation of decision values for dissimilar goods in human ventromedial prefrontal cortex. J Neurosci 29:12315-12320. CrossRef Medline

Cho SS, Strafella AP (2009) rTMS of the left dorsolateral prefrontal cortex modulates dopamine release in the ipsilateral anterior cingulate cortex and orbitofrontal cortex. PLoS One 4:e6725. CrossRef Medline

Cohen MR, Maunsell JH (2011) When attention wanders: how uncontrolled fluctuations in attention affect performance. J Neurosci 31:1580215806. CrossRef Medline

Cohen MX, Cavanagh JF, Slagter HA (2011) Event-related potential activity in the basal ganglia differentiates rewards from nonrewards: temporospatial principal components analysis and source localization of the feedback negativity: commentary. Hum Brain Mapp 32:2270-2271. CrossRef Medline

Craig AD (2002) How do you feel? Interoception: the sense of the physiological condition of the body. Nat Rev Neurosci 3:655-666. CrossRef Medline

Deen B, Pitskel NB, Pelphrey KA (2011) Three systems of insular functional connectivity identified with cluster analysis. Cereb Cortex 21:1498-1506. CrossRef Medline

Delorme A, Makeig S (2004) EEGLAB: an open source toolbox for analysis of single-trial EEG dynamics including independent component analysis. J Neurosci Methods 134:9-21. CrossRef Medline

Figner B, Knoch D, Johnson EJ, Krosch AR, Lisanby SH, Fehr E, Weber EU (2010) Lateral prefrontal cortex and self-control in intertemporal choice. Nat Neurosci 13:538-539. CrossRef Medline

FitzGerald TH, Seymour B, Dolan RJ (2009) The role of human orbitofrontal cortex in value comparison for incommensurable objects. J Neurosci 29:8388-8395. CrossRef Medline

Friston K, Harrison L, Daunizeau J, Kiebel S, Phillips C, Trujillo-Barreto N, Henson R, Flandin G, Mattout J (2008) Multiple sparse priors for the M/EEG inverse problem. Neuroimage 39:1104-1120. CrossRef Medline

Hare TA, O'Doherty J, Camerer CF, Schultz W, Rangel A (2008) Dissociating the role of the orbitofrontal cortex and the striatum in the computation of goal values and prediction errors. J Neurosci 28:5623-5630. CrossRef Medline

Hare TA, Camerer CF, Rangel A (2009) Self-control in decision-making involves modulation of the vmPFC valuation system. Science 324:646648. CrossRef Medline

Hare TA, Camerer CF, Knoepfle DT, Rangel A (2010) Value computations in ventral medial prefrontal cortex during charitable decision making incorporate input from regions involved in social cognition. J Neurosci 30:583-590. CrossRef Medline

Hare TA, Malmaud J, Rangel A (2011) Focusing attention on the health aspects of foods changes value signals in vmPFC and improves dietary choice. J Neurosci 31:11077-11087. CrossRef Medline

Harris A, Adolphs R, Camerer C, Rangel A (2011) Dynamic construction of stimulus values in the ventromedial prefrontal cortex. PLoS One 6:e21074. CrossRef Medline

Henson RN, Mattout J, Singh KD, Barnes GR, Hillebrand A, Friston K (2007) Population-level inferences for distributed MEG source localization under multiple constraints: application to face-evoked fields. Neuroimage 38:422-438. CrossRef Medline

Hillyard SA, Anllo-Vento L (1998) Event-related brain potentials in the study of visual selective attention. Proc Natl Acad Sci U S A 95:781-787. CrossRef Medline

Hopf JM, Vogel E, Woodman G, Heinze HJ, Luck SJ (2002) Localizing visual discrimination processes in time and space. J Neurophysiol 88:20882095. Medline

Hsu M, Anen C, Quartz SR (2008) The right and the good: distributive justice and neural encoding of equity and efficiency. Science 320:10921095. CrossRef Medline

Hunt LT, Kolling N, Soltani A, Woolrich MW, Rushworth MF, Behrens TE (2012) Mechanisms underlying cortical activity during value-guided choice. Nat Neurosci 15:470-476, S1-3. CrossRef Medline

Hutcherson CA, Plassmann H, Gross JJ, Rangel A (2012) Cognitive regulation during decision making shifts behavioral control between ventromedial and dorsolateral prefrontal value systems. J Neurosci 32:1354313554. CrossRef Medline

Jung TP, Makeig S, Humphries C, Lee TW, McKeown MJ, Iragui V, Sejnowski
TJ (2000) Removing electroencephalographic artifacts by blind source separation. Psychophysiology 37:163-178. CrossRef Medline

Kable JW, Glimcher PW (2007) The neural correlates of subjective value during intertemporal choice. Nat Neurosci 10:1625-1633. CrossRef Medline

Kable JW, Glimcher PW (2009) The neurobiology of decision: consensus and controversy. Neuron 63:733-745. CrossRef Medline

Kastner S, Ungerleider LG (2001) The neural basis of biased competition in human visual cortex. Neuropsychologia 39:1263-1276. CrossRef Medline

Kayser J, Tenke CE (2006) Principal components analysis of Laplacian waveforms as a generic method for identifying ERP generator patterns: I. Evaluation with auditory oddball tasks. Clin Neurophysiol 117:348-368. CrossRef Medline

Knight RT, Staines WR, Swick D, Chao LL (1999) Prefrontal cortex regulates inhibition and excitation in distributed neural networks. Acta Psychologica 101:159-178. CrossRef Medline

Knutson B, Rick S, Wimmer GE, Prelec D, Loewenstein G (2007) Neural predictors of purchases. Neuron 53:147-156. CrossRef Medline

Kober H, Mende-Siedlecki P, Kross EF, Weber J, Mischel W, Hart CL, Ochsner KN (2010) Prefrontal-striatal pathway underlies cognitive regulation of craving. Proc Natl Acad Sci U S A 107:14811-14816. CrossRef Medline

Lachaux JP, Rodriguez E, Martinerie J, Varela FJ (1999) Measuring phase synchrony in brain signals. Hum Brain Mapp 8:194-208. CrossRef Medline

Lage-Castellanos A, Martínez-Montes E, Hernández-Cabrera JA, Galán L (2010) False discovery rate and permutation test: an evaluation in ERP data analysis. Stat Med 29:63-74. CrossRef Medline

Lennert T, Martinez-Trujillo J (2011) Strength of response suppression to distracter stimuli determines attentional-filtering performance in primate prefrontal neurons. Neuron 70:141-152. CrossRef Medline

Litt A, Plassmann H, Shiv B, Rangel A (2011) Dissociating valuation and saliency signals during decision-making. Cereb Cortex 21:95-102. CrossRef Medline

Litvak V, Friston K (2008) Electromagnetic source reconstruction for group studies. Neuroimage 42:1490-1498. CrossRef Medline

Mansouri FA, Tanaka K, Buckley MJ (2009) Conflict-induced behavioural adjustment: a clue to the executive functions of the prefrontal cortex. Nat Rev Neurosci 10:141-152. CrossRef Medline

McClure SM, Laibson DI, Loewenstein G, Cohen JD (2004) Separate neural systems value immediate and delayed monetary rewards. Science 306: 503-507. CrossRef Medline

McClure SM, Ericson KM, Laibson DI, Loewenstein G, Cohen JD (2007) Time discounting for primary rewards. J Neurosci 27:5796-5804. CrossRef Medline

Miller EK, Cohen JD (2001) An integrative theory of prefrontal cortex function. Annu Rev Neurosci 24:167-202. CrossRef Medline

Mitchell DG (2011) The nexus between decision making and emotion regulation: a review of convergent neurocognitive substrates. Behav Brain Res 217:215-231. CrossRef Medline

Ochsner KN, Gross JJ (2005) The cognitive control of emotion. Trends Cogn Sci 9:242-249. CrossRef Medline

Oostenveld R, Fries P, Maris E, Schoffelen JM (2011) FieldTrip: open source software for advanced analysis of MEG, EEG, and invasive electrophysiological data. Comput Intell Neurosci 2011:156869. CrossRef Medline

Philiastides MG, Biele G, Heekeren HR (2010) A mechanistic account of value computation in the human brain. Proc Natl Acad Sci U S A 107: 9430-9435. CrossRef Medline

Philiastides MG, Auksztulewicz R, Heekeren HR, Blankenburg F (2011) Causal role of dorsolateral prefrontal cortex in human perceptual decision making. Curr Biol 21:980-983. CrossRef Medline

Plassmann H, O’Doherty J, Rangel A (2007) Orbitofrontal cortex encodes willingness to pay in everyday economic transactions. J Neurosci 27: 9984-9988. CrossRef Medline

Plassmann H, O’Doherty JP, Rangel A (2010) Appetitive and aversive goal values are encoded in the medial orbitofrontal cortex at the time of decision making. J Neurosci 30:10799-10808. CrossRef Medline

Rangel A, Clithero J (2013) The computation of stimulus values in simple choice. In: Neuroeconomics: decision making and the brain (Glimcher PW, Ferh E, eds). London: Academic.

Rose M, Schmid C, Winzen A, Sommer T, Büchel C (2005) The functional 
and temporal characteristics of top-down modulation in visual selection. Cereb Cortex 15:1290-1298. CrossRef Medline

Rushworth MF, Mars RB, Summerfield C (2009) General mechanisms for making decisions? Curr Opin Neurobiol 19:75-83. CrossRef Medline

Seth AK (2010) A MATLAB toolbox for Granger causal connectivity analysis. J Neurosci Methods 186:262-273. CrossRef Medline

Singer T, Critchley HD, Preuschoff K (2009) A common role of insula in feelings, empathy and uncertainty. Trends Cogn Sci 13:334-340. CrossRef Medline

Smallwood J, Schooler JW (2006) The restless mind. Psychol Bull 132:946958. CrossRef Medline

Suzuki M, Gottlieb J (2013) Distinct neural mechanisms of distractor suppression in the frontal and parietal lobe. Nat Neurosci 16:98-104. CrossRef Medline

Swick D (1998) Effects of prefrontal lesions on lexical processing and repetition priming: an ERP study. Brain Res Cogn Brain Res 7:143-157. CrossRef Medline

Tanaka SC, Doya K, Okada G, Ueda K, Okamoto Y, Yamawaki S (2004) Prediction of immediate and future rewards differentially recruits cortico-basal ganglia loops. Nat Neurosci 7:887-893. CrossRef Medline

Tang AC, Sutherland MT, McKinney CJ (2005) Validation of SOBI components from high-density EEG. Neuroimage 25:539-553. CrossRef Medline

Thut G, Théoret H, Pfennig A, Ives J, Kampmann F, Northoff G, PascualLeone A (2003) Differential effects of low-frequency rTMS at the occipital pole on visual-induced alpha desynchronization and visual-evoked potentials. Neuroimage 18:334-347. CrossRef Medline

Toepel U, Knebel JF, Hudry J, le Coutre J, Murray MM (2009) The brain tracks the energetic value in food images. Neuroimage 44:967-974. CrossRef Medline
Tom SM, Fox CR, Trepel C, Poldrack RA (2007) The neural basis of loss aversion in decision-making under risk. Science 315:515-518. CrossRef Medline

Weissman DH, Roberts KC, Visscher KM, Woldorff MG (2006) The neural bases of momentary lapses in attention. Nat Neurosci 9:971-978. CrossRef Medline

Wright ND, Symmonds M, Fleming SM, Dolan RJ (2011) Neural segregation of objective and contextual aspects of fairness. J Neurosci 31:52445252. CrossRef Medline

Wunderlich K, Rangel A, O’Doherty JP (2010) Economic choices can be made using only stimulus values. Proc Natl Acad Sci U S A 107:1500515010. CrossRef Medline

Yamasaki H, LaBar KS, McCarthy G (2002) Dissociable prefrontal brain systems for attention and emotion. Proc Natl Acad Sci U S A 99:1144711451. CrossRef Medline

Yang LY, Jiang H, Rangel KM, Plunkett W (2003) Cisplatin-induced ubiquitination of RNA polymerase II large subunit and suppression of induction by 7-hydroxystaurosporine (UCN-01). Oncol Rep 10:1489-1495. Medline

Zanto TP, Gazzaley A (2009) Neural suppression of irrelevant information underlies optimal working memory performance. J Neurosci 29:30593066. CrossRef Medline

Zanto TP, Rubens MT, Bollinger J, Gazzaley A (2010) Top-down modulation of visual feature processing: the role of the inferior frontal junction. Neuroimage 53:736-745. CrossRef Medline

Zanto TP, Rubens MT, Thangavel A, Gazzaley A (2011) Causal role of the prefrontal cortex in top-down modulation of visual processing and working memory. Nat Neurosci 14:656-661. CrossRef Medline 